\title{
DÓNDE APRENDER A LEER Y ESCRIBIR EN EL AÑO MIL
}

\author{
LEARNING TO READ AND WRITE AROUND YEAR 1000
}

\author{
ANA BelÉn SÁnChez PRIETo \\ Universidad Complutense \\ Universidad de Utrecht
}

\begin{abstract}
Resumen: El hueco creado por la desaparición de las escuelas municipales tras la caída del Imperio Romano fue cubierto por las distintas instancias eclesiásticas, surgiendo de este modo escuelas parroquiales, episcopales y monacales, que además de garantizar la formación básica de los clérigos admitieron en muchas ocasiones a niños laicos no destinados a formar parte de las filas del clero.
\end{abstract}

Palabras clave: Escuela; Historia de la educación; Alta Edad Media; Alfabetismo.

\begin{abstract}
The gap created with the disappearance of the municipal schools after the fall of the Western Roman Empire was filled by the different ecclesiastical institutions, giving birth to schools dependant on parish churches, cathedrals and monasteries. These schools, besides guaranteeing the necessary education of the clergymen, admitted often lay children not destined to join the ranks of the Church.
\end{abstract}

Keywords: School; History of education; Early Middle Ages; Literacy

\section{SUMARIO}

1. Concepción cristiana de la educación y el niño.- 2. Quién podía asistir a la escuela.- 3. Tipos de escuela: a. Escuelas parroquiales. b. Escuelas episcopales. c. Escuelas monásticas. d. La escuela palatina. e. Otras escuelas.- 4. La clase y la disciplina.- 5. Conclusiones.

Durante los siglos que siguieron a la desaparición del Imperio Romano de Occidente, las antiguas provincias, ahora convertidas en reinos independientes bajo sus nuevos gobernantes germánicos, se vieron sometidas a una serie de procesos que si no inmediatamente sí a la larga tendrían como consecuencia una completa mutación de las estructuras no sólo económicas, políticas y sociales a todos evidentes, sino también - y sobre todo - culturales y educativas, que afectaron a todas las clases sociales y a todos los elementos integrantes de la cultura, que, salvo excepciones, quedó confinada preferentemente a los ambientes eclesiásticos ${ }^{1}$.

\footnotetext{
${ }^{1}$ Sobre la sustitución de la aristocracia tradicional romana, educada según patrones muy homogéneos en el arte de la retórica, por una nueva aristocracia intelectual de corte eclesiástico, véanse los primeros capítulos de Pierre RICHÉ, Education et culture dans l'occident barbare. VIeVIII $e^{2}$ siècle, Paris, 1962 , con traducción al inglés por J.J. CONTRENI, Education and Culture in the Barbarian West: Sixth Through Eighth Centuries, Columbia, University of South Carolina
} 
Fue Carlomagno quien en buena medida redescubrió el potencial que ofrecía la escritura para la administración cotidiana del reino, y en su intento de reafirmar la uniformidad de la fe y su celebración estableció que se enseñaran las habilidades básicas de lectura, gramática, música y cómputo en los ámbitos sociales más amplios posibles ${ }^{2}$. Su objetivo no era ni mucho menos la restauración de los estudios clásicos, sino la corrección litúrgica y doctrinal, ni tampoco estaba en condiciones de aspirar a una educación universal, pero los resultados fueron sorprendentes, aunque fugaces ${ }^{3}$.

Naturalmente, para su programa educacional, Carlomagno hubo de apoyarse en la única institución que había mantenido una tradición educativa tras la desaparición de las antiguas escuelas municipales de gramática y retórica: la Iglesia. Con ello los ideales cristianos comenzaron a penetrar, muy tímidamente, la concepción clásica sobre la educación y el niño.

\section{CONCEPCIÓN CRISTIANA DE LA EDUCACIÓN Y EL NIÑO}

Los romanos, como los griegos, nunca tuvieron un especial interés por la infancia. El objetivo de la educación era formar adultos, y sólo los niños precoces que eran capaces de comportarse como adultos a edades muy tiernas eran tenidos en consideración ${ }^{4}$. En la más pura tradición clásica a la que se añadían muchas nociones tomadas del Antiguo Testamento, San Agustín veía en todos los actos del niño la marca del pecado original y aconsejaba el uso de la vara para reprimirlo, sobre todo durante la adolescencia, en la que el muchacho despierta a sus instintos carnales ${ }^{5}$. La irrupción de los germanos no podía cambiar mucho estos planteamientos, en cuanto que la

Press, 1976.

${ }^{2}$ Véase, sobre todo De Litteris Colendis y el párrafo 72 de la capitular Admonitio Generalis. MGH, Capitularia, I, 52-62 y 79 respectivamente. Existe una traducción al inglés en P.D. KING, Charlemagne: Translated Sources, 1986, pp. 209-220 y 232-233. Sobre el alcance de la reforma carolingia, Véase A. GUERREAU-JALABERT "La renaissance carolingienne: modèles culturels, usages linguistiques et structures sociales, "Bibliothèque de l'Ecole des Chartes", 139 (1981), pp. 5-35; F.L. GANSHOF, The Carolingians and the Frankish Monarchy, London, 1971, pp. 125 142 , entre otros.

${ }^{3}$ Poco después de la muerte de Carlomagno, en 825, una capitular de Lotario documenta la gran dificultad de escolarización que existía en el norte de Italia; en esta ocasión el rey estableció Capit. II, p. 327, § 4ss), pero es imposible evaluar el resultado de esta medida. Al año siguiente, un sínodọ romano ordenaba que: "Desde ciertos lugares ha llegado a nuestro conocimiento que no hay ni profesores ni interés por el estudio de las letras. Consecuentemente, que en todos los obispados y parroquias a ellos subordinados y en cualquier otra parte que pueda parecer necesario se tomen diligentemente medidas para señalar profesores y personas instruidas que, conociendo las letras, las artes liberales y la teología sagrada, enseñen regularmente estas materias, porque en ellas todos los órdenes divinos se han hecho claros y manifiestos" ( $M G H$, Conc. II', p. 561, § 7 ss.).

${ }^{4}$ H.I. Marrou, A History of Education in Antiquity, New York, 1956.

${ }^{5}$ P. RICHÉ, Education and Culture, pp. 10-11. 
tradición germánica atribuía al padre (y en su defecto al tío) un poder omnímodo sobre su hijo, al que podía azotar, vender o incluso matar ${ }^{6}$.

Pero Jesús había dicho "dejad que los niños se acerquen a mí, porque de ellos es el Reino de los Cielos" ${ }^{7}$ " de cierto os digo que cualquiera que no reciba el reino de Dios como un niño, jamás entrará en Él" ${ }^{8}$. Y muy poco a poco los ideales evangélicos sobre la infancia fueron calando en algunos autores. En el siglo V el Papa León Magno (440-461) enseñaba que

\begin{abstract}
Amat Christus infantiam, quam primum et animo suscepti et corpore. Amat Christus infantiam humilitatis magistram, innocentiae regulam, mansuetudinis formam. Amat Christus infantiam, ad quam majorum dirigit mores, ad quam senum reducit aetates et eos ad suum inclinat exemplum, quos ad regnum sublimat aeternum ${ }^{9}$.
\end{abstract}

Y en parecidos términos se expresa San Hilario (c. 315-367):

Hi enim patrem sequuntur, matrem amant, proximo velle malum nesciunt, curam opum negligunt: non insolescunt, non oderunt, non mentiuntur, dictis credunt, et quod audiunt verum habent ${ }^{10}$.

Más tarde, el padre del monacato occidental, San Benito (c. 480-c. 547), dio un paso más al declarar en su Regla que los juicios del niño debían ser tenidos en cuenta, "porque Samuel y David, desde su infancia, juzgaron a sus mayores" $"$, y aceptó los consejos de los monjes más jóvenes, "porque a menudo el Señor revela al más pequeño lo que es mejor"12. Y el niño empezó a ser visto como intérprete de la mente de Dios ${ }^{13}$.

Después de San Benito, otros dos monjes, Columbano (543-615) y Beda (672/3-735), así como San Isidoro de Sevilla (c. 560-636), se atrevieron a adentrarse en la sicología infantil, describiéndola en los siguientes términos:

Dic mihi, infans parvulus quantas virtutes habet? Respondit IV: Non laesus meminit, non perseverat in ira, non delectatur pulchra femina, non aliud cogitat vel aliud loquitur ${ }^{14}$.

${ }^{6} \mathrm{Henri}$ Simonnet, Le "mundium” dans le droit de famille germanique, Paris, 1898. Cit. Riché, Education and Culture, pp. 449.

${ }^{7}$ Mt 19:14= Mc 10:14 = Lc 18:16.

${ }^{8}$ Mc 10:15 y Lc 18:1. Otros textos similares, por ejemplo: Mt 18:2-5 = Mc 9:36-37= Lc 9:47-48, Mt 11:2=Lc 10:21. Véase S. LEGASSE, Jésus et l'enfant: Enfants petits et simples dans la tradition synoptique, Paris, 1964.

${ }^{9}$ Serm. VII, 3-4. Cita en P. RICHÉ, Education and Culture, p. 10, n. 38.

${ }^{10}$ In Math., PL 9, 1018.

${ }^{11}$ Reg. LXIII.

${ }^{12}$ "Saepe juniori Dominus revelat quod melius est”. Reg. III.

${ }^{13}$ P. COURCELLE, L'enfant et les sorts bibliques, "Vigiliae Christianae”, 7 (1953), pág. 199. De aquí viene el que una "mano inocente" extraiga las suertes.

${ }^{14}$ IsIDORO, Quaestiones de veteri et novo Testamento, XL. PL, 83, 297. 
Infans humilis est, non laesus meminit, non mulierem videns concupiscit, non aliud ore aliud corde habet ${ }^{15}$.

Puer non perseverat in iracundia, non laesus meminit, non videns pulchram mulierem delectatur, non aliud cogitat, aliud loquitur ${ }^{16}$.

Pero en estos siglos todo está aún por definir. Ni siquiera existe aún un vocabulario preciso para referirse a los grupos de edad que nos ocupan. En teoría el niño es denominado infans hasta los siete años, puer de los siete a los catorce, y adulescens en adelante ${ }^{17}$, pero lo cierto es que el vocabulario fluctúa según los diferentes autores. Por ejemplo, Virgilius Grammaticus divide a los más pequeños entre infans y parvulus ${ }^{18}$, las reglas de San Benito y del Maestro utilizan infans, puer e infantulus para los menores de quince años $^{19}$, y Gregorio de Tours califica de adolescens a un menor de ocho años ${ }^{20}$.

\section{QUIÉN PODÍA ASISTIR A LA ESCUELA}

Los primeros pasos en la educación del niño eran responsabilidad inexcusable de su entorno familiar: de sus padres y, en su defecto, de los padrinos $^{21}$. Pero en esta instancia los autores eclesiásticos entienden por educación más la represión de las tendencias al mal que la alfabetización, que salvo en las familias aristocráticas ${ }^{22}$ sería totalmente inaccesible.

Para ello el niño había de ser enviado a la escuela. Pero lo cierto es que de ella no sabemos prácticamente nada en este periodo. El antiguo sistema romano en el que el niño progresaba desde el magister ludi al rhetoricus, pasando por el grammaticus, parece haber desaparecido por completo, dando lugar a una estructura muy simplificada en la que los distintos niveles de enseñanza permanecerían más o menos indiferenciados. Pero no se ha conservado, si es que existió, ningún manual escolar, ni ningún tratado teórico, ni ninguna representación de una escuela. Por no saber, no sabemos ni siquiera qué nombre recibía. Un glosario anglosajón del siglo VIII incluye

\footnotetext{
${ }^{15}$ Columbano, Ep. 2. MGH, Ep. III, 163, 1.9.

${ }^{16} \mathrm{BEDA}$, In Marc. PL, XCII, 230-31.

${ }^{17}$ Gregorio Magno, Moralia, XI, 46 (PL, 75, 981); Hom. in Evang., I, 19 (PL, LXXVI, 1155); IsIDORO DE SEVILLA, Etim. XI, ii, 4; EUGENIO DE TOLEDO, Satisfactio, MGH, AA, XIV', 129.

${ }^{18}$ Epitomae, II (ed. Tardi, p. 41).

${ }^{19}$ Reg. Ben., LXIII, LXX; Reg. Mag. LIX.

${ }^{20}$ Vitae Patrum, VIII, 2 (MGH, SRM, I-2, 692, 1.20.

${ }^{21}$ Véase por ejemplo FULGENCIO DE RUSPE, Ep. I, cap. X (PL, 65, 309D y ss); GREGORIO MAGNO, Ep. I,17, VII, 26; Dial. IV, 18 (PL, 77, 349B ss.).

${ }^{22}$ Este es con toda probabilidad el caso de Placidia de Verona, la niña de ocho años muerta en el año 532, cuya inscripción sepulcral la describe como "Placidia inlustris puella instructa litteris" (CIIL, V, 3897). Las vidas de santos y otras fuentes ofrecen noticias sobre niños de familias aristocráticas o acomodadas a quienes sus padres buscaban un tutor que se ocupaba de su educación. Véase R. MCKITTERICK, The Carolingians and the Written Word, Cambridge, 1989, p. 222-223.
} 
la siguiente definición: "Ludus litterarum: scola legentium"23; y Beda especifica que

Schola vocatur locus in quo adolescentes litteralibus studiis operam dare et audiendis magistris vacare solent unde schola vacatio interpretatur ${ }^{24}$.

Pero lo cierto es que estas dos fuentes recogen una terminología de época clásica y que en los siglos que nos ocupan schola no significa necesariamente "escuela", ni magister necesariamente "maestro de escuela" 25 , lo cual nos obliga a examinar detenidamente el contexto antes extraer conclusiones de una fuente.

Sólo una cosa es segura: las antiguas escuelas municipales de época romana fueron desapareciendo paulatinamente ${ }^{26}$, y las familias acomodadas se vieron obligadas a asumir la función de éstas, enseñando a leer y a escribir a sus hijos, con o sin la ayuda de un preceptor. Por ejemplo, los padres de Niceto en Génova, Secuano en Borgoña y Gregorio en Clermont pudieron dar a sus hijos una educación básica profana y religiosa ${ }^{27}$.

Aparte de la iniciativa privada factible sólo en las familias aristocráticas o al menos acomodadas, las únicas instancias capaces de ofrecer una instrucción literaria eran las eclesiásticas.

En efecto, para la Iglesia, la alfabetización de una cierta parte de la población no era solamente un deber de caridad cristiana, sino una necesidad, ya que precisaba asegurar el relevo generacional de los ministros del culto: la alfabetización constituía la exigencia mínima para que los clérigos pudieran

${ }^{23}$ J.H. HESSELS, An Eighth-Century Latin-Anglo-Saxon Glossary Preserved in the Library of Corpus Christi College, Cambridge (MS, n. 144), Cambridge, 1890, p. 74.

${ }^{24}$ In primam epistolam Petri, PL, XCIII, 53.

${ }^{25}$ DU CANGE, Glossarium Infimae et Mediae Latinitatis, explica de la siguiente manera "schola" y "magister".

SCHOLA: Generaliter dicebantur aedificia, ubi convenire solent homines plurimi, aut studendi, aut praestolandi, aut conferendi, aut alterius rei gratia, quod probare conantur Henricus Valesius ad lib. 13. Ammiani: ita ut a loco deinde eorum, qui in hisce scholis consistebant, catervae Scholae appellatae fuernit: verbi gratia Scholae Palatinae, seu cohortes variae ad Palatii et Principis custodiam destinatae, quae singulae in suis Scholis excubabant, quarum dignitas varia fuit. pro modo stipendiorum, quae merebant, ac gradus, quem eae obtinebant. Nam, ut ait Vegetius lib. 2, cap. 21: quam in orbem quemdam per diversas cohortes et diversas Scholas milites promovebantur; ita ut exprima cohorte ad gradum quempiam promotus vadat ad decimam cohortem, et rursus ab ea crescentibus stipendiıs cum majore gradu per alias recurrat ad primam. S. Ambrosius in Epist. 1. ad Corinth. cap. 1. initio: Scholae enim sunt, quae positis in se dant dignitatem, ut loci honor hominem faciat gloriosum, non propria laus...

MAGISTER: Titulus honorarius, quo donantur viri ab honoratioribus secundi. Siguen varias páginas de explicación sobre las distintas acepciones de "magister".

${ }^{26}$ Naturalmente, las escuelas municipales no desaparecieron en todas partes al mismo tiempo. Para el caso de la Galia, Véase Pierre RICHÉ, La survivance des écoles publiques en Gaule au Ve siècle, "Le Moyen Age", 63 (1957), pp. 421-436; y Ralf W. MATHISEN, Bishops, Barbarians, and the 'Dark Ages': the'Fate of the late Roman educational institutions in late Antique Gaul, en Ronald B. BEGLEY y Joseph W. KoTERSKI, Medieval Education, New York, Fortham U. Press, 2005 , pp. 1-27. En la España visigoda, lo más probable es que las escuelas municipales desaparecieran antes incluso que en la Galia, haciéndose cargo de la educación de los laicos maestros probablemente clérigos, pero sin que se llegaran a constituir auténticos centros escolares, salvo en el palatium de Toledo. Véase José ORLANDIS, Historia del Reino Visigodo Español, Madrid, Rialp, 1988, 2003, p. 308.

${ }^{27}$ GregOrIO DE TOURS, Vitae patrum, VIII; Vita Secuani, Acta Sanctorum Ordinis Sancti Benedicti, I, 263: "Christianis parentibus educatus". 
ejercer su ministerio. "Que las monjas aprendan a leer"; "que ningún monje desconozca las letras", proclaman las reglas de Cesario, Aureliano y Ferreolo. Necesitaban ser litterati para poder adoctrinar a los fieles, incluso sin saber teología: si carecían de la cultura necesaria para componer sus propios sermones, podían utilizar los homiliarios ya compilados. Y por supuesto necesitaban conocer los ritos de la misa y los sacramentos: "No es posible edificar al pueblo si no es por medio de la lectura" 28 .

El laico que quería unirse a la iglesia de su diócesis, según los Statuta ecclesiae antiqua, debía pasar por las órdenes menores: portero, lector, exorcista, acólito, subdiácono y diácono, antes de ser ordenado presbítero. Por debajo del subdiaconado, los clérigos podían casarse y llevar una vida prácticamente igual a la de los laicos, con ciertos beneficios a cambio de prestar pequeños servicios a la Iglesia, pero en todos los casos se les suponía un cierto grado de alfabetización. Los exorcistas tenían que conocer los exorcismos recogidos en el libro que recibían de mano del obispo y que debían aprender de memoria ${ }^{29}$; los salmistas tendrían voz clara y educada para que su canto mueva los ánimos ${ }^{30}$; del lector dice San Isidoro que debían conocer los significados de las palabras e interpretar la lectura con la entonación conveniente al contexto ${ }^{31}$.

Pero las fuentes dejan entrever que algunos muchachos no destinados expresamente al presbiterado ni procedentes de las clases altas tuvieron oportunidad también de recibir algún tipo de educación elemental en estos centros, lo que sin duda fue aprovechado para dar una nueva orientación, mucho más bíblica y religiosa en general, a los estudios, incluso en aquellos casos en que se admitía a muchachos no destinados a recibir las órdenes sagradas. La única excepción a este caso sean, quizás, las escuelas dependientes de las stationes de los notarios laicos en Italia ${ }^{32}$.

\section{TIPOS DE ESCUELA}

Las Institutionum disciplinae, atribuidas tradicionalmente a San Isidoro pero que en realidad hay que datar entre la muerte de Isidoro y principios del siglo VIII, la educación comenzaba en la infancia con el aprendizaje de las primeras letras, siguiendo luego el estudio de las artes liberales clásicas: el trivium (gramática, retórica y dialéctica) y el quadrivium

\footnotetext{
${ }^{28}$ Concilio provincial de Narbona (589), c. 11.

${ }^{29}$ IsIDORO, De eccl. Off. 2, 13, 3-4 (PL 83, 793): Exorcista ... mandet memoriae de Scripturarum sacramentis ... hi cum ordinantur .... accipiunt de manu e.piscopi libellum in quo scripti sunt exorcismi. Recoge aquí san Isidoro lo dispuesto en el concilio Cartaginense IV, c. 7 $(P L, 84,200)$. cit. M.C. DIAZ Y DÍAZ, Introducción a SAN ISIDORO DE SEVILLA, Etimologías, Madrid, BAC, $2000^{3}$, p. 73.

${ }^{30}$ ISIDORO, De eccl. Off., 2, 12, 1-3 (PL 83, 792).

${ }^{31}$ De ecclesiasticis Officiis, II, 11, 2. Véase la cita más abajo.

${ }^{32}$ A. PETRUCCI, Book, Handwriting and School, en Writers and Readers in Medieval Italy. Studies in the History of written Culture, Yale University Press, 1995, pp. 59-76, p. 74.
} 
(aritmética, geometría, música y astronomía), materias que se complementaban con rudimentos de medicina, derecho y filosofía ${ }^{33}$.

En el año 796, Alcuino escribió desde Tours a su antiguo pupilo Eanbald, que acababa de ser elevado a la cátedra arzobispal de York. Después de las habituales congratulaciones y de algunos consejos generales, Alcuino pasa a la escuela y cómo debe ser organizada:

Provee maestros tanto para los chicos como para los clérigos adultos.

Separa en clases aquellos que han de estudiar los libros, los que han de practicar la música eclesiástica, y los que se ocuparán en transcribir. Mantén un maestro separado para cada clase y mira que los muchachos no puedan andar por ahí haraganeando, ocupados en juegos inútiles o haciendo tonterías $^{34}$.

Sin embargo, no parece que ni el currículo del Institutionum pseudoisidoriano ni la especialización por materias propuesta por Alcuino tuviera un reflejo real en el mundo educativo de comienzos de la Edad Media, ya que las estructuras escolares eran extraordinariamente fluidas. A menudo las distintas fases se concentraban en una única institución escolástica y salvo en las mayores la especialización sería imposible.

Lo que sí es posible distinguir es el ámbito en el que se desarrollaba la instrucción. Puesto que, como se ha dicho, dependían básicamente de instituciones eclesiásticas, es la categoría de estas y los recursos disponibles para cada una lo que determinaba la respectiva escuela. Distinguiremos, así pues, entre escuelas parroquiales, catedrales o episcopales y monásticas.

\section{a. Escuelas parroquiales}

La preocupación por la formación de los muchachos en las áreas rurales es una constante en la legislación eclesiástica de estos siglos. En la Galia, tan pronto como el año 529 y bajo la presidencia de Cesario de Arlés, el concilio de Vaison ordenó que los presbíteros tomaran en torno a sí a un grupo de lectores, que debían "psalmos parare, divinis lectionibus insistere", con vistas a que al menos algunos de ellos alcanzara las órdenes mayores, según era costumbre también en Italia ${ }^{35}$. Las vidas de santos ofrecen algunos ejemplos de estas escuelas parroquiales: Germano, futuro obispo de París, se trasladó a Avallon juntamente con su primo para educarse con un clérigo

\footnotetext{
${ }^{33}$ Véase J. MARTín VÁzQUEZ, Sobre el origen visigodo de las Institutionum Disciplinae, "Faventia" 1 (1979), pp. 35-46.

${ }^{34}$ MGH, Epistolae Karolini aevi, II, 169. Cit. A.F. WEST, Alcuin and the Rise of the Christian Schoots, pp. 75-76.

${ }^{35}$ George WADDINTON, A History of the Church from the Earliest Ages to the Reformation, London, 1835, II, p. 399 . De Italia, aparte de esta información, hay una noticia del año 715, en un pleito sobre jurisdicción entre dos parroquias rurales. Véase RICHE, Education and Culture, pp. $408-409$.
} 
pariente suyo que enseñaba en la escuela parroquial en un castrum $^{36}$. En Chartres, un presbítero de nombre Chirmiro regentó una escuela en la primera mitad del siglo $\mathrm{VI}^{37}$, y poco después San Gaugerico recibió su primera educación religiosa en castrum Ebosium (Carigman) $^{38}$. Y a principios del siglo VII Praeyecto fue a una escuela en Issoire, conviniéndose para las comidas con un diácono de la ciudad ${ }^{39}$.

Las primeras noticias de algo muy similar para la Península Ibérica son poco posteriores, y desde el siglo VI se encuentras escuelas anejas a algunas parroquias ${ }^{40}$, pero hay que esperar a los cánones de los Concilios Toledo VI (638) y Mérida (666) para encontrar alguna legislación al respecto, aunque desgraciadamente es más ambigua que la de Vaison, limitándose a apremiar a los libertos de las iglesias a que entreguen sus hijos a éstas "causa eruditionis" $"$.

De la Francia carolingia, la información es también menos abundante y más imprecisa de lo que desearíamos. Más arriba se ha mencionado la iniciativa de Carlomagno ordenando a los curas rurales que admitieran en sus escuelas tanto a niños libres como de condición servil, y les enseñaran gramática, cálculo y canto ${ }^{42}$, pero desgraciadamente no sabemos en qué medida estas disposiciones tuvieron efecto. No mucho después Teodulfo de Orleans dictó unos estatutos en los que recomendaba que dentro de su episcopado los clérigos erigieran escuelas en las villas y lugares para la educación de los "hijos de los fieles", insistiendo en que la educación debía ser gratis y que la recompensa de los profesores debía ser el progreso de sus alumnos ${ }^{43}$ :

Presbyteri per villas et vicos scolas habeant. Et si quilibet fidelium suos parvulos ad discendas litteras eis commendare vult, eos suscipere et docere

\footnotetext{
${ }^{36}$ ForTunatụ, Vita Germani, II, 5 y III, 8 (AA, IV-2, 12): "Deinde cum Avallone castro cum stratidio propinquo puer scolis excurreret... Hinc ad parentem suum sanctum Scupilionem Lausea se conferens moribus honestis alitus et institutus est".

${ }^{37}$ Vita Launomaris, Acta Sanctorum Ordinis Sancti Benedicti, ed. J. Mabillon, I, 335: "Parentis ... cuidam venerabili presbytero Chirmiro sacris imbuendum litteris ac conversatione tradiderunt. Beatus autem Chirmirus intra urbem Carnotum fulgebat docrina".

${ }^{38}$ Vita Gaugerici, MGH, SRM, III, 642.

${ }^{39}$ Vita Praejecti, MGH, SRM, V, 224: "Paladius innuit puero [Praejectol ad quemdam diaconem vocitantem Bobbonem sibi rogatum prandii cause secum accessurum". Estos ejemplos están tomados de P. RICHÉ, Education and Culture, p. 279-281, donde pueden encontrarse otros similares.

${ }^{40}$ Justo FERNÁNDEZ ALONSO, La cura pastoral en la España romanovisigoda, Roma, Instituto Español de Estudios Eclesiásticos, 1955, p. 396.

${ }^{41}$ Toledo VI (638) c. 10: "Et etenim decet ut hi quorum parentes titulum libertatis de familiis ecclesiae perceperunt, intra ecclesiam cui obsequium debent, causa eruditionis enutriantur". Mérida (666), c. 18: "Ut omnes parochiani presbyteri ... de ecclesiae suae familia clericos sibi faciant; quos per bonam volontatem ita nutriant ut te officium sanctum digne peragant et ad servitium suum aptos eos habeant".

Sobre la legislación educativa de los concilios visigodos, Véase Francisco MARTín HERNÁNDEZ, Formación del Clero en la Iglesia Visigótico-Mozárabe, Toledo, Estudio Teológico de San Ildefonso, 1979.

${ }^{42}$ Admonitio Generalis, MGH, Capit. I, p. 60.

${ }^{43}$ PL 105, cols. 191-210 c. 19. MGH, Cap. epis. I, p. 116. Rosamond MCKITTERICK, The Frankish Kingdoms under the Carolingians, New York-London, Longman, 1983, p. 146.
} 
non renuant, sed cum summa caritate eos doceant ... Cum ergo eos docent, nihil ab eis pretii pro hac re exigant nec aliquid ab eis accipiant excepto quod eis parentes caritatis studio sua voluntate obtulerint.

Una generación más tarde, los obispos Herard de Tours (855-66) y Walter de Orleans (869?-91), repitieron la medida de urgir a los párrocos rurales que mantuvieran una escuela, pero, añadían, "si es posible"

Los estatutos de Teodulfo de Orleans fueron importados en Inglaterra, donde circularon en varias versiones, en latín e inglés, y aunque nunca fueron formalmente promulgadas, por lo que no se puede dudar de que instituciones similares existieron en la isla, y que allí también los clérigos rurales se formaban en escuelas locales regidas por los propios párrocos ${ }^{45}$.

Algunos inventarios de bienes conservados demuestran que las pequeñas parroquias rurales disponían de una modestísima biblioteca, que presumiblemente utilizarían para que los niños ejercitaran sus habilidades de lectura $^{46}$.

Es de suponer que cuando los obispos visitaban las parroquias de su diócesis se interesarían por los niños que estudiaban en ellas. Cuando el obispo de Trier visitó Carignan, el presbítero le presentó a los niños que estaba preparando para recibir las órdenes sagradas ${ }^{47}$. El concilio de VIII de Toledo (653) precisó que los candidatos a las órdenes mayores debían examinarse ante el obispo y demostrar saber de memoria el salterio, los cánticos, los himnos y el ritual ${ }^{48}$.

No debieron de ser pocos los niños laicos que acudieron a estas escuelas, y desde principios del siglo XI se multiplicaron con el apoyo de los mercaderes que deseaban para sus hijos una instrucción básica en lectura, escritura y aritmética que les permitiera continuar los negocios familiares ${ }^{49}$.

También las niñas, incluso las de condición más humilde, tenían acceso a estas escuelas, si sus circunstancias familiares se lo permitían. Tomás de Cantimpré, en el siglo XIII, relata una historia encantadora ${ }^{50}$ :

\footnotetext{
${ }^{44}$ Capitula Herardi c. 17 (PL 121, 765): Ut scholas presbyteri proposse habeant et libros emendatos. Capitula a Walterio reverendo pontifice compresbiteris promulgata in sinodo apud Bullensem fundum II, 6 (MGH Cap. episc. 189): Ut unusquisque presbiter suum habeat clericum, quem religiose educare procuret et, si possibilitas illi est, scolam in ecclesia sua abere non negligat sullerterque caveat, ut, quos ad erudiendum suscitit, caste sinceriterque nutriat.

${ }^{45}$ Nicholas ORME, Medieval Schools. From Roman Britain to Renaissance England, Yale University Press, 2006, pp. 39-40.

${ }^{46}$ J.J. CONTRENI, The Carolingian Renaissance: Education and Literary Culture, en Rosamond MCKITTERICK (ed, The New Cambridge Medieval History, vol. II: c. 700-c.900, Cambridge
University Press, 1995, pp. 709-757, p. 715 .

${ }^{47}$ Vita Gaugerici, $M G H$, SRM, III, 642.

${ }^{48}$ Toledo VIII (653), c. 8.

${ }^{49}$ Didier LETT, The Child in Christendom, Fifth-Thirteenth Centuries, en Danièle ALEXANDREBIDON; Didier LETT, Children in the Middle Ages. Firth-Fiftheenth Centuries, Notre Dame, Indiana, 1999, p. 46 .'

${ }^{50}$ Bonum universale de apibus, I, 23, ed. DOUAE, 1627, pp. 93-94. Cit. y traducido por Didier LETT, The Child in Christiendom. Fith-Thirteenth centuries, p. 40-41.
} 
Una pequeña campesina suplicó a su padre que le comprara un salterio para poder aprender a leer. “¿Pero cómo”, contestó él, "podría comprarte yo un salterio, si apenas puedo ganar lo suficiente para comprarte pan cada día?" La niña calló contrariada, pero después vio en un sueño aparecer a la bienaventurada Virgen, sosteniendo dos salterios en las manos. Animada por esta visión se dirigió de nuevo a su padre. "Hija mía", le dijo el padre, "ve cada domingo a visitar a la maestra de la parroquia; pídele que te dé unas pocas lecciones y trata de hacerlo lo mejor posible para ganar uno de los dos salterios que has visto en las manos de la Virgen". La niña obedeció, y percatándose de su celo, sus compañeros reunieron el dinero suficiente para comprarle el libro que ella había deseado tanto.

Aunque la fuente es del siglo XIII, y por lo tanto fuera del período que nos ocupa, es muy probable que la situación en las aldeas no hubiera cambiado demasiado con respecto a la décima centuria.

El nivel de estas escuelas debía de ser bastante elemental, cumpliéndose las exigencias mínimas, que no debían de ir mucho más allá de lo estrictamente necesario para celebrar, lo que en España era equivalente a saber leer y utilizar el libellus officialis o liber manualis, que el obispo entregaba al presbítero al tiempo de su ordenación y del que nunca debían separarse, como lo expresaba simbólicamente el hecho de que a su muerte este libro era enterrado con ellos. Es probable que el lamento de Liciniano de Cartagena sobre el bajo nivel cultural del clero, que no alcanzaba los requerimientos especificados por San Gregorio Mango en Regula Pastoralis, se refieran a los clérigos formados en este tipo de escuelas ${ }^{51}$. ¿Habría estudiado en una de ellas aquel presbítero ignorante del latín que, al decir de San Bonifacio, bautizaba "in nomine patria et filia et spiritus sancti"? ${ }^{52}$. Quienes quisieran continuar progresando más allá del nivel elemental que la mayor parte de las escuelas parroquiales rurales estaban en condiciones de ofrecer debían acudir a la escuela episcopal.

\section{b. Escuelas episcopales}

Las escuelas episcopales están relativamente mejor documentadas que las parroquiales en prácticamente todos los territorios de la cristiandad occidental, aunque desgraciadamente sigue faltando mucha información al respecto.

\footnotetext{
${ }^{51}$ Ep. 1, 5 (PL 72, 690). Rafael GONZÁLEZ FERNÁNDEZ, Cultura e ideología del siglo VI en las cartas de Liciniano de Cartagena, "Antigüedad y Cristianismo", 12 (1995), pp. 269-374. M.C. DÍAZ Y DÍAZ, en su introducción a la trad. esp. de las Etimologías de S. Isidoro (Madrid, $\mathrm{BAC}, 2000^{3}$ ) p. 74 , plantea la cuestión de si no se tratará más que de un rigorismo a la vieja usanza, cuando do se pregunta si en lugar de tanta ciencia no bastará con que conozcan y prediquen a Cristo crucificado.

${ }^{52}$ SAN BONIFACIO, Carta ${ }^{\circ}$. 68, julio de 746. Trad. inglesa de C.H. TALBOT The Anglo-Saxon Missionaries in Germany, New York, 1954, n. 31, p. 119.
} 
En Francia se puede documentar alrededor de una veintena de ellas. En el norte Vermand, Reims, Paris, Metz y Tongres son las más importantes, y en el sur Bourges, Poitiers, Clermón, Lyon y Périgueux ${ }^{53}$.

En el reino visigodo, existieron con seguridad al menos en Toledo, Mérida, Sevilla, Palencia y Narbona, y Juan de Bíclaro, Masona de Mérida, Leandro de Sevilla y Eutropio de Valencia fueron sólo algunos de los beneficiarios de este tipo de escuelas. Quizá la de Mérida sea la mejor conocida, gracias a las Vitae Sanctorum Patrum Emeritensium ${ }^{54}$. En ellas se hace mención de que el futuro obispo Masona y un joven llamado Augusto vivieron en su juventud junto con sus compañeros "in domo egregiae virginis Eulaliae", entregado al servicio divino en la iglesia y a los oficios litúrgicos. Uno de los clérigos emeritenses llamado Paulo, hizo entrar en la escuela a su sobrino Fidel, "mandó que se le tonsurara y ofreciéndole para siempre al Señor, como a otro Samuel en el templo, le fue instruyendo diligentemente de día y de noche, de manera que en muy pocos años le fue enseñando todo el oficio eclesiástico y toda la biblioteca de las Sagradas Escrituras" ${ }^{55}$.

En Inglaterra, Sigeberht de East-Anglia, que se había convertido al cristianismo durante su exilio en la Galia, en los años 630, "deseando copiar lo que había visto en la Galia, se apresuró a fundar una escuela para la educación de los muchachos en el estudio de las letras. En este proyecto fue asistido por el obispo Félix que, llegado desde Kent, le proveyó de profesores y maestros según la práctica de Canterbury" ${ }^{56}$. En el norte hallamos un movimiento similar con la misión de los monjes irlandeses, que dio como fruto la fundación de la catedral monástica de Lindisfarne en el año 635, donde su primer obispo, Aidan, reunió a un grupo de muchachos ingleses para instruirlos ${ }^{57}$. Por supuesto, las escuelas episcopales inglesas, sobre todo la de Canterbury, conoció un nuevo período de florecimiento en el 699 con la llegada a la isla de Teodoro de Tarso, nombrado arzobispo de Canterbury, y su compañero Adriano ${ }^{58}$; entre multitud de alumnos ingleses e irlandeses que reunieron es sin duda Aldhelmo el más conocido.

En la Francia Carolingia, las escuelas catedralicias fueron objeto de singular atención en la asamblea conciliar reunida en el 822 en Attigny. Allí los obispos decidieron que cada diócesis debía tener al menos una, o dos o tres en caso de diócesis excepcionalmente grandes ${ }^{59}$. Provisiones similares se repitieron en el sínodo de París de 829, en donde además los obispos requirieron la creación de escuelas reales, lo que al parecer nunca se llevó a

\footnotetext{
${ }^{53} \mathrm{P}$. RICHÉ, Education and Culture, p. 282.

${ }^{54}$ PL 80152 ss. Hay una nueva edición por J.N. GARVIN, con introducción y comentarios, Washington, 1946.

${ }^{55}$ Vitae 5, 13. Cit. MARTín HernándeZ, Formación del Clero, p. 9.

${ }^{56} \mathrm{BEDA}$, Historia Eclesiastica III, 18.

${ }^{57}$ BEDA, Historia Eclesiastica III, 26.

${ }^{58} \mathrm{BEDA}$, Historia eclesiastica IV, 2.

${ }^{59} M G H$ Conc. II, ii, No. 42 , c. 3.
} 
cabo $^{60}$. En este mismo concilio se requirió a los obispos a que llevaran consigo algunos de sus estudiantes, de modo que quedara patente el apoyo episcopal a sus respectivas escuelas. Aquí parece, no obstante, que se hacía una clara distinción entre la educación de los muchachos destinados a ser canónigos de los destinados a ser simplemente curas rurales ${ }^{61}$.

En Germania, el arzobispo Arno de Salzburgo, en un concilio provincial celebrado en Rispach en el año 789, ordenó a sus sufragáneos que se aseguraran de que cada presbítero poseyera una copia correcta del sacramentario y de que entendía las Escrituras y celebraba la misa de acuerdo a las exigencias de la Iglesia de Roma ${ }^{62}$.

Sin embargo, desgraciadamente, de la organización y materias estudiadas se puede saber muy poco. Casi lo único que se puede asegurar es que la escuela estaba aneja a la catedral y a la residencia del obispo (domus ecclesiae) y sus alumnos, básicamente familiares del obispo, hijos de clérigos, huérfanos, niños dedicados por sus padres a la iglesia y algunos muchachos procedentes de las escuelas parroquiales ${ }^{63}$, vivían en un régimen de internado bajo a tutela del obispo o del archidiácono, que aún no habían perdido sus funciones docentes, o de un prepósito. En Inglaterra, sin embargo, al final de la época que nos ocupa o incluso hacia los siglos XI y XII, parece ser que los niños debieron abandonar la residencia común, debiendo alojarse entonces en las casas particulares de los canónigos, donde recibían comida y ropa a cambio de servicios domésticos ${ }^{64}$. En general la edad de ingreso en estas escuelas debía de ser bastante temprana, en torno a diez años.

En España, el Liber Ordinum ha conservado el rito y las oraciones que se pronunciaban sobre el niño en el momento de ser admitido en la escuela episcopal ${ }^{65}$, dando a entender que desde aquel momento, incluso antes de haber aprendido a leer, ya empezaban a realizar modestos servicios litúrgicos bajo la dirección del prepósito ${ }^{66}$. También para él había una bendición al tiempo de serle conferido el cargo, implorando para él "el espíritu de toda discreción, la luz inefable de la sabiduría divina y la abundancia de la medicina celeste para que, viviendo rectamente, instruya al mismo tiempo con su palabra y corrija en las costumbres a la grey de los clérigos" ${ }^{67}$. Para el mismo fin al archidiácono se le entregaba una vara, al

\footnotetext{
${ }^{60} M G H$, Conc. II, ii, No. 50, c. 30 .

${ }^{61}$ Concilio de Aquisgrán de 816. Cit. J.J. ConTrenI, The Carolingian Renaissance, p. $713-$ 714.

${ }^{62} M G H$, Conc. II.i, no. 22, cc. 4-5, p. 198.

${ }^{63} \mathrm{P}$. RICHÉ, Education and Culture, p. 282-283. 316.

${ }^{64} \mathrm{~K}$. EdWARDS, The English Secular Cathedrals in the Middle Ages, Manchester, 1967 ${ }^{2}$, p.

${ }^{65}$ Liber ordinum, n. 38: Oratio super paryulum quem parentes ad doctrinam offerunt. Y n. 39: "Benedictio super parvulum qui in ecclesia ad ministerium detondiutr".

${ }^{66} \mathrm{P}$. RichÉ, Education and Culture, p. 285-286.

${ }^{67}$ Liber Ordinum, 53. Traducción de F. MARTín HERNÁNDEZ, Formación del Clero en la Iglesia Visigótico-Mozárabe, p. 8.
} 
tiempo que se le recordaba su deber de ser prudente en el discurso y pródigo en la enseñanza ${ }^{68}$.

Por fortuna, los cánones de los concilios toledanos arrojan alguna luz sobre su funcionamiento general. Su origen parece remontarse al concilio II de Toledo (527), que ordenó que se establecieran para la formación del clero:

\begin{abstract}
Respecto a los que la voluntad de sus padres destinó desde los primeros años de su infancia al clericato, establecemos que después de tonsurados y puestos en la clase de los escogidos, deben ser enseñados por el prepósito en la casa de la iglesia, bajo la inspección del obispo; y cuando llegaren a cumplir los dieciocho años de edad, se les pregunte delante de todo el clero y del pueblo si quieren o no casarse. Si por inspiración de Dios respondieren que quieren vivir en castidad, prometiendo observarla sin casarse, serán puestos bajo el yugo suavísimo del Señor como aspirantes de una vida más austera; y ante todo, después de la prueba de su profesión, serán ordenados de subdiáconos a los veinte años de edad; y si llegaren a cumplir los veinticinco, habiendo pasado el tiempo sin juicio y lesión, ascenderán a diácono si son capaces, a juicio del obispo, de cumplir con las obligaciones de tales ${ }^{69}$.
\end{abstract}

De acuerdo con el concilio II de Toledo, los candidatos debían ser examinados por el obispo, para comprobar si eran capaces de cumplir sus funciones con los debidos conocimientos previamente a su ordenación como diáconos.

De todos modos, no podemos saber hasta qué punto se cumplieron las estipulaciones conciliares, incluso en las diócesis de los obispos presentes en aquel concilio, que fueron relativamente pocos y todos de la Cartaginense. Medidas similares se repitieron en el Concilio IV de Toledo de $633^{70}$, lo que nos hace pensar que o bien las escuelas episcopales de estas diócesis tuvieron tanto éxito que los prelados quisieron hacerlas extensivas a las demás, o que la negligencia en su establecimiento o mantenimiento hizo necesaria la repetición de la orden.

Originariamente, los propios obispos debieron de ser los encargados de enseñar en sus escuelas, y de hecho "cátedra" significa tanto sede episcopal como magistral; pero gradualmente en un proceso que culminó hacia el siglo VII, las labores pastorales, administrativas e incluso políticas fueron apartando a los obispos de su función docente, debiendo entonces delegarla en algunos de los miembros más cualificados de sus "familias", apareciendo entonces el

\footnotetext{
${ }^{68}$ Liber ordinum, 15: Sit baculum nobis et virga indisciplinatis...; sit sermone cautus et scientia providus".

${ }^{69}$ c. 1. VIVES, Concilios visigóticos e hispano-romanos, Madrid-Barcelona, 1963, p. 42-43.

${ }^{70} \mathrm{C} .24$ : Es oportuno establecer que, cuando haya entre los clérigos muchachos o adolescentes, residan todos en un solo edificio dentro del recinto eclesiástico, a fin de que pasen los años de esta edad tan inclinada a las pasiones no en ocasiones de vicio, sino ẹ la posibilidad de formarse en los saberes eclesiásticos, confiados a un varón de costumbres bien probadas, al que tengan por maestro de su formación y ejemplo de moralidad. Y si hay entre ellos huérfanos, sean cuidados por una especial tutela del obispo, a fin de que su vida se vea libre de asechanzas y su hacienda de menoscabo por parte de gentes malvadas. Quienes se opusiesen a estas disposiciones, sean recluidos en monasterios, para que sus espíritus inconstantes e insumisos se sometan a la represión de una disciplina más severa.
} 
magister scholarium, magister scholarum, scholasticus o capischola ${ }^{71}$, que probablemente desempeñó además alguna otra función en la catedral, y con frecuencia se le consideraba el sucesor más cualificado del obispo a la muerte de éste.

Puesto que los muchachos ingresaban en la escuela a edad muy temprana (excepto los procedentes de las escuelas parroquiales), aprenderían allí sus primeras letras, pero la formación allí recibida era tanto moral y espiritual como intelectual. Del plan de estudios nos da cierta idea el IV concilio de Toledo:

La ignorancia es madre de todos los errores; hay que evitarla, singularísimamente entre los obispos de Dios, que recibieron la misión de enseñar al pueblo... Conozcan, pues, los sacerdotes las escrituras santas y los cánones, para que toda su acción consista en la predicación y en la enseñanza, y para que edifiquen a todos los fieles tanto por su conocimiento profundo de la fe como por la corrección ejemplar de sus obras ${ }^{72}$.

El primer paso para la mayoría de estos muchachos debió de ser el de lector, bajo la dirección del primicerius lectorum, que les enseñaba a leer correctamente los textos, según las exigencias especificadas por san Isidoro:

\begin{abstract}
Quien vaya a ser ascendido a este rango deberá estar versado en la doctrina y los libros y conocerá a fondo los significados de las palabras, a fin de que en el análisis de las sentencias sepa dónde se encuentran los límites gramaticales, dónde prosigue la lectura, dónde concluye la oración. De este modo dominará la técnica de la expresión oral sin obstáculos, a fin de que todos comprendan con la mente y con el sentimiento, distinguiendo entre los distintos tipos de expresión, y expresando los sentimientos de la sentencia: ora a la manera del que expone, ora a la manera del que sufre, ora a la manera del que increpa, ora a la manera del que exhorta, ora adaptándose a los tipos de expresión adecuada ${ }^{73}$.
\end{abstract}

Otros, sin embargo, eran dedicados a la modulatio davidica, esto es, al canto de salmos e himnos, bajo la dirección del primicerius cantorum.

Es posible que en algunas catedrales se impartieran ambas materias a todos los muchachos, pero en general ambas enseñanzas debieron de estar separadas $^{74}$. En el siglo VI, Epifanio, futuro obispo de Pavía, se convirtió en lector a los ocho años, y simultáneamente servía como "notario" al obispo Crispino $^{75}$, lo cual quiere decir probablemente que al mismo tiempo aprendía las técnicas de lectura pública y de la burocracia administrativa, en este caso bajo la supervisión del senior scribarum ${ }^{76}$.

\footnotetext{
${ }^{71}$ M. DeAnesly, Medieval Schools, en Cambridge Medieval History, V, pp. 767-78.

${ }^{72}$ C. 25.

${ }^{73}$ De eccleciasticis officiis, II, $11,2$.

${ }^{74} \mathrm{P}$. RichÉ, Education and culture, p 123.

${ }^{75}$ EnNodio de Pavia, Vita Epifanii, 8. PL, 63. 207-240.

${ }^{76}$ Liber ordinum, $\mathrm{n}^{\mathrm{o}} .21$.
} 
El Institutionum Disciplinae, de finales del siglo VII, describe lo que pudo ser el plan de estudios de las escuelas episcopales. El aprendizaje comenzaba por el estudio de las letras, hasta llegar a conocer el acento de las sílabas y distinguir el valor de las palabras y brillar en las disciplinas liberales. El salterio era el silabario oficial, y cuando los muchachos tenían ya una cierta soltura en la lectura comenzaban a estudiar la gramática, primero con el tratado de Elio Donato y luego con el Ars grammatica de San Julián de Toledo. El cálculo básico también era objeto de enseñanza. Aparte de en las materias "básicas", los muchachos eran instruidos en las sacrae litterae, divina scientiae, doctrina ecclesiastica, spiriutalis scriptura, etc., o sea, en las Sagradas Escrituras y otras lecturas como vidas de santos, cánones y escritos de algunos padres (latinos). En el caso de los aprendices de notarios, el aprendizaje de técnicas de estenografía y ars dictandi, serían también imprescindibles.

Es muy posible que en estas escuelas episcopales, al igual que en las parroquiales, se educaran algunos muchachos laicos, no destinados a recibir las órdenes sagradas. En la España visigoda, como se ha visto más arriba, los alumnos de la escuela episcopal, al alcanzar la edad de dieciocho años, debían ser interrogados sobre si querían continuar progresando en el estado eclesiástico o si deseaban casarse, con lo que de tomar esta última opción volverían al siglo. Asimismo, se ha apuntado que es posible que algunos nobles enviaran a sus hijos a educarse en casa de los obispos, sobre la base de una serie de textos que parecen destinados a la educación de jóvenes aristócratas más que de futuros clérigos ${ }^{77}$. En Inglaterra, según Beda, el obispo Aidan de Lindisfarne (635-51) tenía en su casa tanto clérigos como laicos, y a todos les hacía recitar los salmos y leer las escrituras ${ }^{78}$. De Juan de Beverly sabemos que solía salir a cabalgar con jóvenes laicos, y que en una ocasión uno de ellos, Herebald, que estaba aprendiendo a leer, tuvo un accidente $^{79}$. Finalmente, Wildrid, arzobispo de York (669-678) recibía en su casa a los hijos de nobles anglosajones, que se los encomendaban sin que tuvieran aún una idea clara de si querían llegar a ser clérigos o guerreros ${ }^{80}$.

\footnotetext{
${ }^{77}$ Roger COLLINS, Literacy and the laity in early medieval Spain, en R. MCKITTERICK (ed.), The Uses of Literacy in Early Medieval Europe, Cambridge, 1990, pp. 109-133, p. 116. Los textos en cuestión son la Gramática de Julián de Toledo, ciertas piezas retóricas anadidas a la Historia de Wamba, los versos de Eugenio II de Toledo sobre secciones de las Etimologías y un pequeño corpus poético con obras atribuidas a Eugenio, que ha sido caracterizado como "Speculum per un nobile visigoto". Véase también N. Messina, Pseudo-Eugenio de Toledo. Speculum per un nobile visigoto, Santiago de Compostela, 1983.

${ }^{78}$ BEDA, Historia Eclesiastica, III.5.

${ }^{79}$ BEDA, Historia Eclesiástica, V.6.

${ }^{80}$ Eddius StePhANus, 44-5. Para más ejemplos, Véase Susan Kelly, Anglo-Saxon lay society Society and the Written Word, en Rosamond MCKITTERICK (ed.), The Uses of Literacy in Early Medieval Europe, Cambridge, 1990, 36-62, p. 59-60.
} 


\section{c. Escuelas monásticas}

Nacido en Oriente, el monacato fue importado a Occidente en el siglo IV. En un momento en que las persecuciones religiosas habían acabado, los monasterios ofrecían un estilo de vida radical a aquellos que deseaban llevar el ideal cristiano hasta sus últimos extremos; como consecuencia, en ellos no había lugar a los estudios seculares. Sin embargo, para los siglos VI-VII muchos monasterios habían perdido ya los prejuicios rigoristas y puede decirse que se convirtieron en auténtico refugio de los restos que quedaban de la civilización clásica. De sus escuelas salió la élite intelectual de estos siglos, capaz de dar lugar al destello, fugaz pero resplandeciente, del renacimiento carolingio.

La población infantil y adolescente en los monasterios altomedievales debía de ser considerablemente numerosa. La oblación de niños por sus padres era una práctica corriente en todos los territorios de occidente. Agradecimiento por una victoria militar o de una curación milagrosa, influencia de una personalidad fuerte como la de San Columbano, etc., o incluso muerte de los progenitores o imposibilidad de mantener económicamente a los pequeños son algunos de los motivos que pudieron impulsar a los padres a entregar a sus hijos a un monasterio. En otros casos, la iniciativa partía de los propios muchachos, que a edades tempranas mostraban inclinación monástica, con o sin la aquiescencia de sus padres.

Los ejemplos de niños entrados en el monasterio a muy tierna edad son muy numerosos ${ }^{81}$, por lo que unos pocos bastan como botón de muestra. El rey Oswy de Northumbria ofreció a su hija de un año como acción de gracias por una victoria militar ${ }^{82}$; Beda fue entregado al abad Benedicto Biscop a la edad de siete años ${ }^{83}$, la misma que Eugendo cuando entró en Condat ${ }^{84}$. Wilfrid era un adolescente cuando por propia elección y con la bendición de su padre decidió abrazar la vida religiosa en el monasterio de Lindisfarne ${ }^{85}$, y el también adolescente Achivus, futuro tercer abad de Agaune, entró en Grigny a pesar de la objeción de sus padres ${ }^{86}$. Beda cuenta que en el convento de monjas de Barking vivía un pequeñín de tres años, llamado Æsica, "que por su tierna edad era criado y educado en las celdas de las vírgenes de Dios" ${ }^{\prime 7}$. En España, en los monasterios fundados por San Fructuoso, los padres que deseaban hacerse monjes podían hacerlo, llevando

\footnotetext{
${ }^{81}$ Hasta ahora nadie ha superado el estudio de Maike de JONG, Kind en klooster: aspeckten van de schenking van kinderen aan kloosters in het Frankische Rijk (500-900), Amsterdamse historische reeks 8, Amsterdam, 1986. Existe una versión inglesa con el título de In Samuel Image: Child Oblation in the Early Medieval West, Leiden, 1996.

${ }^{82}$ BEDA, Historia Eclesiastica, III, 24.

${ }^{83}$ BEDA, Historia Eclesiastica, V, 24.

${ }^{84}$ Vita Eugendi, $M G H$, SRM, III, 100.

${ }^{85}$ BEDA, Historia Eclesiastica, V, 19.

${ }^{86}$ Vitae Abbadum Acaunensium, MGH, SRM, III, 179.

${ }^{87}$ BEDA, Historia Eclesiastica, IV, 8.
} 
a sus hijos con ellos, y aunque los niños eran alojados en dependencias separadas, mientras eran pequeños podían visitar a sus padres siempre que quisieran $^{88}$. Sin embargo, san Bonifacio tuvo que vencer un sinfín de obstáculos paternos para poder hacer realidad su vocación monástica ${ }^{89}$. Finalmente, constatamos también la existencia de niños, generalmente esclavos rescatados, en los monasterios que se iban fundando en el siglo VIII en la Germania en proceso de cristianización ${ }^{90}$.

De todos modos, en ocasiones se puede apreciar cierto rechazo hacia convertir los monasterios en guarderías, sobre todo en los legisladores más rigoristas. Según la regla de Cesario de Arlés, la edad mínima para que una niña fuera admitida en el monasterio era seis años, o sea "a la edad en que pueden a prender a leer y a obedecer" ${ }^{91}$; Aureliano de Arlés suspendía la admisión hasta los doce años ${ }^{92}$. No parece ser, sin embargo, este el caso de la Regula Magistri ni la de San Benito.

Indudablemente, los monasterios debían proveer a la educación de los pequeños, y de hecho la existencia de escuelas monásticas está más que probada. Pero desgraciadamente, las fuentes no permiten conocer gran cosa sobre las escuelas monásticas aparte de su existencia. Como en el caso de las otras dos clases mencionadas más arriba, la educación en las letras se compaginaba perfectamente con la educación religiosa y moral, hasta el punto de que las fuentes no hacen diferencia entre ambas. Por ejemplo, Wilfrid, tras entrar en el monasterio de Lindisfarne, "se aplicó a aprender y practicar todo aquello que conducía a la pureza y devoción monástica; pues era de mente despierta, aprendió muy pronto los salmos y otros libros antes de recibir la tonsura" $" 93$.

El buen funcionamiento de las escuelas monásticas es uno de los principales objetivos de la epístola De litteris colendis, en la que Carlomagno argumentaba la necesidad de una educación adecuada paralelamente a la oración y otras prácticas piadosas. El monje ideal, especifica el rey, es el monje instruido, porque los que buscan complacer a Dios con la corrección de su vida deben también complacerlo con la corrección de su dicción, en cuanto que según la Escritura "te justificarás por la palabra y por la palabra

\footnotetext{
${ }^{88}$ FRUCTUOSUS, Reg. mon. comm. 6 (PL, 87, 115): "Illos tamen parvulos quos adhuc in crepundia videmus terneculos propter misericordiam concessam habeant licentiam quando voluerint ad patrem aut matrem pergant, ne fortasse parentes pro ipsis in vitio murmurationis cadant; quia solet pro eis grandis in monasterio murmuratio evenire".

${ }^{89}$ Willibald, Vida de San Bonifacio , c. 1. Traducción inglesa de C.H. TALBOT, The AngloSaxon Missionaries in Germany, New York, 1954, p. 28.

${ }^{90}$ Véase P. Riché, Education and Culture, p. 433.

${ }^{91}$ CESARIO DE ARLÉS, Regula ad virgines, 5. PL 67, col. 1108C-D. .

${ }^{92}$ Regula, 17. PL, 68, 38.

${ }^{93}$ BEDA, Historia Eclesiastica, V, 19.
} 
te condenarás" ${ }^{94}$, y porque el desconocimiento del latín puede inducir a errores e incluso herejías.

El abad confiaba a los niños del monasterio a un monje anciano, que las reglas designan con diversos términos, siendo los más corrientes formarius, senior y decanus ${ }^{95}$, cuyo papel, a decir de Isidoro, era más bien el de un orientador o formador, ya que su ocupación principal era vigilar día y noche a los muchachos, impedir que cogiesen malos hábitos, enseñarles la regla, etc. El término de decanus hace referencia al tamaño del grupo que tenía encomendado: una decena.

En el monasterio el tiempo se ordenaba a lo largo del día según los oficios monásticos. Madrugaban muchísimo para recitar nocturnos y maitines y después acudían a la escuela monástica, donde leían y cantaban los versos que habían aprendido. Según la Regula Magistri, del siglo VI, las horas de clase eran tres. Después acudían al oficio de la hora sexta y tras ella al refectorio, donde eran escrupulosamente supervisados por un monje adulto. Después de completas, alrededor de las seis de la tarde, y siempre en silencio, los niños volvían a su dormitorio, separado del resto de los monjes ${ }^{96}$.

El capítulo 22 de la regla de Aureliano de Arlés describe el trabajo de los "perparvuli infantes"

In omni ministerio, sive in ordine psallendi, aut legendi, vel operandi, vicibus sibi succedant, absque sancto abbate; et nimis senibus, et perparvulis infantibus, aut certe ita infirmis, ut surgere omnino non possint, non compellantur facere, pro eo quod non praevalent.

Sobre los estudios comunes en las escuelas parroquiales y episcopales, los pequeños monjes debían aprender además la regla correspondiente ${ }^{98}$. Pero además, una vez superados los prejuicios rigoristas de los primeros siglos, al menos algunas escuelas monásticas se afanaron por inculcar en sus oblatos no sólo las letras imprescindibles para leer la Biblia y los textos litúrgicos, sino también las artes liberales, como el único camino posible para comprender debidamente las Sagradas Escrituras en su triple sentido - histórico, moral y artístico - y desempeñar su labor pastoral. San Isidoro pedía a sus monjes que repartieran su tiempo entre la oración, la lectura y las disputas intelectuales entre ellos mismos, porque "son mejores los gramáticos que los heréticos,

${ }^{94}$ Mt 12: 37. La traducción completa de la epístola De litteris colendis puede encontrarse en WEST, Andrew FLEMING, Alcuin and the Rise of the Christian Schools, Princeton, 1892, repr. Honolulu, Hawaii, 2004, pp 49-51 y LAISTNER, Thought and Letters in Western Europe AD 500 900, $2^{\text {nd }}$ ed. rev., London, 1957., p. 195-197.

${ }^{95}$ Formarius, Regula Caesarii, 37 (PL, 67, 1114); Regula Ferreoli, 17 (PL, 66, 965). DECANUS, Reg. mon. comm. Fructuosi, 3 y 12 (PL 87, 1100 y 1120); Regula Magistri XI'(existe una traducción al español por I. Gómez); Isidori Reg. mon., XIV (PL, 83, 883).

${ }^{96}$ D. LETT, The Child in Christendom, p. 50-51.

${ }^{97}$ PL 68, 390.

${ }^{98} \mathrm{La}$ lectura frecuente de la Regla es un lugar común en la mayor parte de ellas. Por ejemplo, la de San Fructuoso establece que "sed inter utrosque foveantur quousque quantulumcumque regulam conoscant et semper instruantur ut sive sint puere sive puellae monasterio provocentiur ubi habitare futuri eruntur". 
pues ... la doctrina de los gramáticos puede aprovechar a nuestra vida, en tanto que sea empleada para mejores usos" 99 .

De las escuelas monacales salió la élite religiosa e intelectual de los primeros siglos medievales, y muchos de ellos llegaron a ocupar las sedes episcopales más importantes. San Gregorio Magno, San Leandro de Sevilla, San Agustín de Canterbury, San Willibrord y San Bonifacio son sólo algunos de ellos.

Pero además es muy probable que los monasterios sirvieran también de centros de enseñanza para niños y niñas destinados a regresar, tras terminar su educación, al mundo, o incluso tenemos algunos indicios que nos permiten pensar que en algunos casos en los medios rurales las escuelas monásticas actuaban como escuelas locales. Por ejemplo, Wilfrid fue confiado al monasterio de Lindisfarne para recibir educación como laico (laicus capite), y sólo después adquirió condición eclesiástica ${ }^{100}$. El hijo de Carlos Martel, Pepino, fue confiado al monasterio de Saint-Denis cuando era muy pequeño ${ }^{101}$, y Eginardo y varios bastardos carolingios fueron educados en diferentes escuelas monásticas ${ }^{102}$. En tiempos de Carlomagno apenas podemos dudar de que tal costumbre continuaba, no sólo por las disposiciones de la De litteris collendis y la Admonitio Generalis, sino también por algunos otros indicios, que permiten vislumbrar su grado de aplicación. Por ejemplo, la crónica de Saint Riquier por Hariulf conserva la descripción de una procesión litúrgica, en la cual tomaron parte tanto los niños laicos de la escuela externa como los niños de la escuela interna de la abadía ${ }^{103}$. También las Gesta abbatum Lobbiensis, hace referencia a una escuela externa en Lobbes ${ }^{104}$. Ya se ha mencionado como los estatutos de Teodulfo de Orleans ordenaban a los párrocos de su diócesis mantener escuelas para los "hijos de los fieles" sin esperar gratificación a cambio; pero además fijó varios monasterios dependientes del arzobispado para que pudieran estudiar en sus respectivas escuelas los familiares de los clérigos que lo deseaban. Y el mismísimo Alcuino no mostró una liberalidad mayor desde su monasterio de Tours; a él se le atribuyen ciertos versos que alguien inscribió en la bifurcación de dos caminos cerca de Salzburgo:

Caminante que te apresuras a lo largo de la calzada, detén un momento tus pasos y lee atentamente estas líneas. Un camino te conducirá a satisfacer tus deseos de beber a una taberna, pero el otro está bendecido con una doble ventaja. Elige, pues, oh caminante, qué camino elegirás: si el de ir a beber o el de ir a aprender de sagrados libros. Si quieres beber tendrás

${ }^{99}$ Sentencias, 3, 13-11. PL 83, col. 688.

${ }^{100}$ S. Kelly, Anglo-Saxon lay society, p. 59-60.

${ }^{101}$ D. LETT, The Child in Christendom, p. 47.

${ }^{102}$ MCKITTERICK, The Carolingians and the Written Word, 220.

${ }^{103}$ Cit. R. MCKITTERICK, The Frankish Kingdoms under the Carolingians, p. 146, y The Carolingians and the written Word, p. 220.

${ }^{104}$ c. 23. $M G H$, SS XXI, pp. 327. 
que pagar dinero, pero si quieres aprender tendrás lo que buscas por nada ${ }^{105}$.

Es verdad que apenas muerto Carlomagno, Luis el Piadoso decretó en Aquisgrán en el 817 que sólo los futuros monjes debían ser instruidos en las escuelas monásticas ${ }^{106}$, probablemente para evitar que los muchachos laicos pudieran disturbar la vida monástica, o, lo que es peor, influir negativamente sobre los oblatos. La medida no era nueva, pues varios siglos antes Cesario de Arlés había prohibido taxativamente a las monjas que admitieran en su escuela a ninguna muchacha que no estuviera ligada formalmente a la comunidad $^{107}$.

Pero lo cierto es que al menos en algunos sitios la orden real fue incumplida, o al menos los monjes fueron lo bastante hábiles como para cumplir la orden real y al mismo tiempo seguir prestando instrucción a los lugareños, y por ejemplo en San Gall se adoptó la medida de separar físicamente las dos escuelas, colocando la escuela externa para los niños laicos fuera de los muros de la abadía, al norte, mientras que la escuela interior para los oblatos se mantuvo dentro de la abadía, al este. Incluso parece ser que hasta mediados del siglo IX la misma persona estaba a cargo de las dos escuelas: el monje Iso ${ }^{108}$, que sin embargo hacia el 851 cedió la dirección de la escuela interna al irlandés Marcelo. Ratperto, Notker Balbulus y Notker el Físico y los cuatro Ekkehards enseñaron en ambas ${ }^{109}$ (Véanse Figs. 1 y 2, al final del artículo, pp. 32 y 33).

Sin duda el ejemplo de San Gall fue seguido también en otras abadías, si bien los rastros dejados en la documentación son pocos. Es probable que la escuela de San Pedro, situada a cierta distancia del monasterio de Corbie, en Picardía, fuese también una escuela exterior, pues la Vida de Anskar describe que cuando ejercía como maestro en ella debía recorrer un trecho hasta llegar al monasterio ${ }^{110}$. Igualmente en Saint Hubert, en las Ardenas, la existencia de la doble escuela está documentada para el siglo XI, pero dado que la refundación del monasterio en ese emplazamiento data del 825 , es muy

${ }^{105}$ PL 101, 757, Carm. CXIX. Traducción inglesa por A.F. WEST, Alcuin, p. 68-69.

${ }^{106} M G H$, Cap. I, No. 170 , c. 45 , p. 346.

${ }^{107}$ Regula ad virgines, c. 7. PL, 67, col. $1108 \mathrm{D}$.

${ }^{108}$ M.L.W. LAISTNER, Thought and Letters, pp. 209.

${ }^{109}$ MCKITTERICK, The Frankish Kingdoms under the Carolingians, pp. 146-147. Se ha apuntado la posibilidad de que las dos escuelas sean sin embargo una y la misma, pero en diferentes fases. La escuela externa serviría de escuela elemental, a la que todo el mundo podría acceder, y donde aparte de la lectura y la escritura, se enseñarían nociones básicas de cálculo, canto y gramática; posteriormente, los que tuvieran vocación monástica continuarían estudios más avanzados en la escuela interna. Véase Walter HORN, On the author of the Plan of St Gall and the relation of the plan to the monastic reform movement, en Johannes DUFT (ed.), Studien zum St Galler Klosterplan, St Gall, 1962, pp. 103-27, y R. MCKITTERICK, The Carolingians and the Written Word, p. 221 .

${ }^{110} \mathrm{MGH}$, SS, II, p. 687. 
posible que ambas estuvieran funcionando ya por aquel entonces ${ }^{111}$. Es posible que Saint Riquier también tuviera una escuela semejante ${ }^{112}$.

Y si los niños laicos eran admitidos en las escuelas monásticas para recibir allí una educación literaria, no hay ninguna razón para suponer que las niñas no lo fueran también en los conventos de monjas ${ }^{113}$. Por ejemplo, la Vita Liutbergae informa sobre que la santa ofrecía instrucción a niñas que después regresaban a sus casas ${ }^{114}$.

En Alemania, al menos entre los siglos IX y XI, muchos monasterios femeninos admitían a muchachas nobles que tras su educación regresaban al mundo en lugar de tomar los hábitos. Así, el duque Liudolfo envió a sus cinco hijas a la abadía de Gandersheim ${ }^{115}$; tres de ellas permanecieron en él y fueron nombradas abadesas, pero dos se casaron ${ }^{116}$. Y la reina Matilde, esposa de Enrique I de Alemania, había estudiado en el monasterio de Herford ${ }^{11}$. Otros monasterios como Meschede, Vreden, Freckenhors, Essen y Geresheim, todos fundaciones del siglo IX, fueron con toda probabilidad otros de los centros que acogían jóvenes para su educación ${ }^{118}$. Finalmente, de Inglaterra permite suponer una situación semejante el hecho de que Edith, hija del conde Godwine y más tarde mujer de Eduardo el Confesor, se había educado en los años 1030-1040 con las monjas de Wilton Abbey, y tenía reputación de ser entendida en música, gramática y lenguas, que sin duda aprendió en la abadía $^{119}$.

\section{d. La escuela palatina}

También la existencia de escuelas palatinas más o menos estables para los hijos de los nobles parece estar constatada para la mayoría de los grandes reinos occidentales. Lamentablemente, la peor documentada de todos ellos es la que presumiblemente se habría alojado en la Toledo visigoda, de cuya

\footnotetext{
${ }^{111}$ M.L.W. LAISTNER, Thought and Letters, p. 209.

${ }^{112}$ M.M. HiLdebrandT, The External School in Carolingian Society, Education and Society in the Middle Ages and Renaissance 1, Leiden, 1992, pp. 91-93.

${ }^{113}$ Rosamond MCKITTERICK, Women and literacy in the early middle ages, en R. McKITTERICK, Books, Scribes and Learning in the Merovingian Kingdoms, $6^{t h}-9^{t h}$ Centuries, Aldershot, Variorum, 1994, n. XIII, pp. 39-41.

${ }^{114}$ Vita Liutbergae, c. 35. MGH SS IV, pp. 44.

${ }^{115}$ Cuya colección de manuscritos sugiere un alto nivel cultural. Véase R. MCKITTERICK, Women and literacy in the early Middle Ages, p. 40.

${ }^{116}$ D. LETT, The Child in Christendom. Fifth-Thirteenth Centuries, p. 48.

${ }^{117}$ Vita Mathildis Reginae Antiquior, cap. 1, MGH, SS rerum Germanicarum, 66, p. 112: Cum autem puericia transacta virile robur intraret eiusque tranctarent parentes, cuius femine thalamum genere propitateque non disparem adiret, illorum interea pervenit ad aures quandam in monasterio Herevordensi pulcherrimam fuisse puellam nomina Machtildam literalis studio discipline erudiendam, activa atque contemplativa unde queritur vita, cuius generositas haud minus futuri claruit sponsi.

${ }^{118}$ Ulrich FAUST, Die Frauenklöster in Niedersachsen, Schleswig Holstein und Bremen, Germania Benedictina 11, St Ottilian, 1984.

${ }^{119}$ P. STAFFORD, Queen Emma and Queen Edith, Oxford, 1997, pp. 258-9. Cita N. ORME, Medieval Schools. From Britain to Renaissance England, p. 46.
} 
existencia, sin embargo, no se puede dudar ${ }^{120}$. Poco más se puede decir de la Galia merovingia. Aquí ciertamente existía un tutor real, el más conocido de los cuales fue el de Childeberto II, llamado Gogo, gran amigo de Venancio Fortunato, pero no sabemos si entre sus funciones estaba el ocuparse de la educación de los niños enviados a la corte por sus padres. Su papel parece haber consistido más bien en proveer para ello, pues la vida de san Audoino relata que él y sus hermanos fueron enviados al rey y que éste los entregó a ciertos "varones ilustres" para que los educaran; y lo mismo sucedió con Leodegario, a quien Clotario II entregó al obispo Dido de Poitiers ${ }^{121}$. Las cortes merovingias parecen haber sido no obstante un foco de atracción de muchachos que destacaban por su talento, como el joven Patroclo, que aunque de pequeño había cuidado los rebaños de su familia, dado el gran aprovechamiento que había demostrado en la escuela, fue recomendado a Nunnio, consejero de Childeberto I, lo mismo que el futuro obispo de Metz Arnulfo, que fue enviado al rector palatii Gundulf ${ }^{122}$.

Algo más de luz arrojan las fuentes sobre la época de Carlomagno y sus sucesores. Durante su primera estancia en Italia en el año 774, al llegar a Roma, Carolomagno fue recibido por "los niños que estaban aprendiendo sus letras" 123 , por lo que no parece posible dudar de que bajo los auspicios del Pontífice existía algún tipo de escuela para los más pequeños. De una posterior visita de Carlomagno a la Urbe, del año 787, puntualiza Adhemar de Chabannes que "Rex Karolus iterum a Roma artis grammaticae et computatoriae magistros secum adduxit in Franciam ut ubique studium litterarum expandere iussit"124 y no hay motivos para pensar que la propia corte no fue uno de los lugares donde estos maestros fueron establecidos.

Aunque no hay por qué tomar al pie de la letra el relato de Notker de San Gall, que escribió una semi-legendaria biografía de Carlomagno durante los años 880, un pasaje de ella resulta tremendamente significativo: A su vuelta de una campaña militar, el rey convocó a su presencia a los pueri cuyo cuidado y educación había encomendado al maestro Clemente y les pidió sus escritos y poemas, percatándose de que los ejercicios de los infimi y mediocres estaban adornados con arte y talento, mientras que los nobiles eran fatuos y perezosos.

Entonces el muy sabio Carlos, imitando al Juez eterno, colocó a los que habían trabajado bien a su derecha y les dijo: 'Doy gracias, hijos míos,

\footnotetext{
${ }^{120}$ Las fuentes son muy tardías y no dicen nada sobre su organización. P. Riché, L'Education à l'époque wisigothique: les Institutionum Disciplinae, "Anales toledanos" 3 (1971), 171-80.

${ }^{121}$ Vita Audoini, c. 1. MGH SRM V, p. 554. Passio Leudegarrii II, c. 1, MGH SRM V, pp. 324-5. Ambas citas tomadas de P. RICHE, Education and Culture, p. 74.

${ }^{122}$ GREGORIO DE TOURS, Vitae Patrum, IX, c. 1. MGH SRM 1-2, pp. 702-703. Vita Arnulfi c. 3, MGH SRM, II, $p_{1} 433$. Citas tomadas de Ian WOOD, Administration, law and culture in

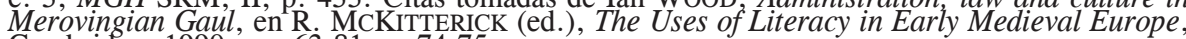
Cambridge, 1990, pp. 63-81, p. 74-75.

${ }^{123}$ Liber pont. I: 497: [Papa] direxit universas scholas militiae una cum patronis simulque pueris qui ad didicendas litteras pergebant".

${ }^{124}$ Hist. libri tres, II, 8 (MGH, SS, IV, 118).
} 


\begin{abstract}
porque habéis seguido mis órdenes, dando lo mejor de vosotros. Ahora continuad esforzándoos para alcanzar la perfección y os veréis recompensados con monasterios y obispados, y siempre seréis honrados a mis ojos'. Entonces se volvió con gran severidad a aquellos que estaban a su izquierda, y con fiera mirada que parecía traspasar las conciencias, con desprecio, les espetó las siguientes palabras: 'Vosotros, nobles, hijos de los grandes, ricos en tierras y de alta cuna, vosotros habéis ignorado mis órdenes y descuidado el estudio de las letras, regocijándoos en la pereza y en juegos pueriles'. Y habiendo dicho esto volvió su augusta cabeza y levantó su diestra invicta a los cielos, pronunciando esta promesa: ‘ $i$ Por los cielos! No me impresiona vuestra nobleza ni vuestra apariencia elegante, incluso si otros las admiran. Sabed que si no tapáis con estudio vuestra anterior negligencia no obtendréis nada bueno de Carlomagno ${ }^{125}$.
\end{abstract}

Uno de estos muchachos de alta cuna educados en palacio fue sin duda el conde Wala, de quien Pascasio Radberto dice que "se aplicó al estudio de las artes liberales entre los jóvenes del palacio, demostrando su alta nobleza en sus maneras y la honestidad de sus sentimientos ${ }^{126}$.

Para el reinado de Carlos el Calvo la corte se nos presenta como un centro de estudio de las artes liberales para aquellos jóvenes que, siendo de familias aristocráticas, habían completado ya sus primeros estudios. Así, poco después del 867, Herefrid, que en el 887 sería ordenado obispo de Auxerre, fue enviado a la corte de Carlos el Calvo por su tío el obispo Walter de Orleans para que pudiera completar su educación en las artes liberales en la escuela palatina junto con otros nobles destinados a altos cargos eclesiásticos; y hacia el 864, Radbod (futuro obispo de Utrecht entre 899 y 917) acudió a la corte con sus compañeros Esteban y Mancio (ambos también futuros obispos de Lieja y Châlons-sur-Marne respectivamente) para estudiar con el "filósofo" Manno ${ }^{127}$. De ello parece que la escuela de la corte de Carlos el Calvo fue más bien un centro de estudios superiores.

No parece ser ese el caso de la de Alfredo el Grande en Inglaterra, que organizó en la corte una escuela para su hijo menor, que así pudo recibir, junto con los hijos de los nobles y algunos otros niños, una educación bilingüe en inglés y latín. La escuela de la corte de Alfredo el Grande estaba, por tanto, destinada para los futuros oficiales reales, que, en palabras del propio rey, precisarían una educación tanto intelectual como moral y física ${ }^{128}$.

${ }^{125}$ Gesta Karoli Magni, I.3. MGH, SRG, n.s., 12. Trad inglesa por L. THORPE, Two Lives of Charlemagne, London, 1970, pp. 95-96.

${ }^{126}$ Paschasius RadBertuS, Epitaphium Arsenii, ed. Pertz, p. 35. Cit. Matthew InNeS, $A$ Place of Discipline': Carolingian Courts and Aristocratic Youth, in Catherine CUBITT (ed.), Court Culture in the Early Middle Ages, Turnhout, 2003, pp. 59-76, p. 70.

${ }^{127}$ Heiric de Auxerre, Gesta episcoporum Autissioderensium, MGH SS XIII, p. 400. Vita Radbodi Traiectensis episcopi, MGH SS XV, p. 569. Ambas notas tomadas de R. MCKITTERICK, The Palace School of Charles de Bald, en J.L. NELSON; M.T. GIBSON, Charles the Bald, Court and Kingdom, $2^{\text {nd }}$ ed, Aldershot, 1990, pp. 326-339, p. 329.

${ }^{128}$ La bibliografía sobre la política educacional de Alfredo es muy numerosa. Citaremos, a modo de ejemplo: D.A. BuLLOUGH, The educational tradition in England from Alfred to Alfric: Teaching utriusque linguae, en La Scuola nell'Occidente latino dell'Alto Medioevo, Settimane di Studio del Centro Italiano di Studi sull'Alto Medioevo, 19, 15-21 aprile 1971, Spoleto, 1972, vol. 2 pp. 453-494. Rep. in Carolingian Renewal: Sources and Heritage, Manchester-New York 1991, pp. 297-334, p. 297-300; R. ABELS, Alfred the Great: War, Kingship ad Culture in Anglo- 


\section{e. Otras escuelas}

Además de estas escuelas, encontramos en algunos lugares otras escuelas nacidas espontáneamente de las necesidades del lugar. En la Galia, a mediados del siglo VI, por ejemplo, el eremita Patroclo abrió su propia escuela en Néris ${ }^{129}$ y en España, Valerio del Bierzo (m. 695), en el siglo VII, tomaba consigo a los niños de los pueblos cercanos en los meses de verano y les enseñaba las letras y el salterio; en invierno, los niños volvían al valle con sus familias ${ }^{130}$.

\section{LA CLASE Y LA DISCIPLINA}

Desgraciadamente, no poseemos ninguna representación gráfica ni descripción de una clase. Los coloquios de Ælfric Bata mencionan únicamente bancos. No debía de haber pupitres, pues como las representaciones gráficas que poseemos de escritores y copistas de esta época no los tienen, es de suponer que tampoco los habría en las escuelas. Los muchachos, por tanto, debían escribir cruzando su pierna izquierda sobre la derecha y apoyando el soporte escriptorio sobre el muslo, con lo que una simple tabla de madera haría las veces de pupitre (Véase Fig. 3, al final del artículo, p. 34).

El material escriptorio más utilizado habrían sido las tablillas de madera o marfil, rebajadas por el centro y rellenas por una o ambas caras con cera y a veces recubiertas de cuero, sobre las que se escribía con un stylus o graphium de metal, hueso o marfil ${ }^{131}$. San Benito estipula en su Regla que todos los monjes tengan libros, styli y tablillas enceradas a su disposición ${ }^{32}$. El papiro (charta) todavía estaba disponible en Europa como material escriptorio $^{133}$ y se utilizaba sobre todo para componer borradores de documentos, por lo que también debió de estar disponible para los ejercicios escolares. Si en algún momento escaseaba, la corteza de árbol podía hacer las veces $^{134}$. El pergamino, sobre todo el de buena calidad, era carísimo, y a veces difícil de encontrar en las cantidades adecuadas, incluso para personas

Saxon England, London and New York, Longman, 1998, p. 54 y 229; Simon KEYNES y Michael LAPIDGE, Alfred the Great. Asser's Life of King Alfred and other contemporary sources, London, Penguin Books, 1983, p. 31-36, etc.

${ }^{129}$ GREGORIO DE TOURS, Vitae Patrum, IX (MGH, SRM, 1-2, 703): "Pueros erudire coepit in studiis litterarum". Cit. P. RICHÉ, Education and Culture, p. 279.

${ }^{130}$ VALERIUS, Ordo querimoniae, PL, 87, 448ss.

${ }^{131}$ P. RICHÉ, Education and Culture, p. 459-460.

${ }^{132}$ Regula Benedicti LV.

${ }^{133}$ H. PIRENNE, Le commerce du papyrus dans la Gaule mérovingienne, "Académie des Inscriptions et Belles-Lettres. Comptes rendus de séances de l'année 1928”, pp. 178-191.

${ }^{134}$ Vita Liudgeri, ed. Diekamp., pp. 12-13: Qui statim ut ambulare et loque poterat, coepit colligere elliculas et corticis arborum quibus ad luminaria uti solemus et quidquid tale invenire poterat, ludentibusque pueris aliis, ipse consuit sibi de illis collectionibus quasi tibellos. Cumque invenisset sibi liquorem cum festucis imitabatur scribentes et afferebat nutrici suae quasi utiles libros custiendos. 
con recursos suficientes ${ }^{135}$, pero sobre todo en las escuelas dependientes de instituciones que disponían además de scriptorium, es muy posible que los niños pudieran utilizar los restos de pergamino que quedaban después de cortar las hojas para hacer los libros. Sobre estos últimos materiales se escribía con tinta con una pluma de caña o de ave.

Al menos en las escuelas monásticas las clases no debían ser muy numerosas, ya que la Regula Magistri agrupaba a los niños por décadas, esto es, de diez en diez, bajo la supervisión de un maestro ${ }^{136}$, y Ælfric Bata menciona que el maestro podría tener un ayudante ${ }^{137}$. También según la Regula Magistri, las horas de clase eran tres.

La mayor lacra de la enseñanza durante la temprana Edad Media fue sin duda la escasez de libros, y ello a pesar de que a partir de principios del siglo IX, con la reforma impulsada por Carlomagno, la producción de libros se multiplicó por doquier, pero éstos siguieron siendo escasos y raros, y el propio Alcuino, desde su monasterio de Tours, se lamenta de que necesita los libros de que había dispuesto en la escuela de York, y pide a Carlomagno permiso para enviar un mensajero que los traiga.

Para trasportar y guardar los libros se utilizaba, al menos en Irlanda, una cartera o cartapacio de cuero ${ }^{138}$. La Hisperica Famina, una obra irlandesa del siglo VII, describe uno de ellos como hecho de cuero blanco, cosido en forma de cuadrado y provisto de doce cuerdas, que servían para que el estudiante pudiera llevar su libro colgado del cuello, y otros autores irlandeses hablan de carteras que sus dueños llevan consigo bajo el brazo o sobre sus hombros, sin duda de forma muy parecida a los escolares actuales y de todos los tiempos.

La escasez de libros acrecentaba la importancia del maestro, por lo que en buena medida la educación de sus discípulos dependía de sus conocimientos previos y de su propio talento didáctico. De ahí la importancia de los trabajos de compilación de autores anteriores sobre un tema determinado, que tanto florecieron por esta época.

La enseñanza muy probablemente se estructuraba en forma de diálogo, pues la mayor parte de las obras didácticas que se han conservado tienen esta forma, por ejemplo, la Ortografía de Alcuino, que es claramente un tratadito dedicado a principiantes. Introducimos aquí un ejemplo, tomado también de Alcuino (Pippini regallis et nobilissimi iuvenis disputatio cum Albino scholastico) a modo de ejemplo, en donde Alcuino enseña a su alumno Pipino:

\footnotetext{
${ }^{135}$ BRAUlio DE ZARAGOZA, ep. 14: Membrana nec nobis sufficient et ideo ad dirigendum vobis deficient, sed pretium direximus unde si iusseritis comparare possitis.

${ }^{136}$ Regula Magistri, L: In his tribus horis infantuli in decada sua in tabulis suis ab uno litterato litteras meditentur.

${ }^{137}$ N. ORME, Medieval Schools, p. 45.

${ }^{138}$ Llamada en irlandés tiag o tiag libuir y en latín hibérnico scetha. Cit. Pádraig P. Ó NÉILL, Celtic Britain and Ireland in the early middle ages, en E. LEEDHAM-GREEN y T. WEBBER (eds.), The Cambridge History of Libraries in Britain and Ireland, volume I, to 1649, pp. 85-86.
} 
Pipino: ¿Qué es una letra?

Alcino: El guardián de la historia.

P. ¿Qué es una palabra?

A. La engañadora de la mente.

P. ¿Qué crea la palabra?

A. La lengua.

P. ¿Qué es la lengua?

A. Algo que golpea el aire.

P. ¿Qué es el aire?

A. El protector de la vida

$\ldots$

En general los alumnos eran bastante dóciles, y las enseñanzas o las palabras del maestro nunca eran contestadas ni objeto de controversia ${ }^{139}$.

Los niños debían aprender sus lecciones de memoria, y no se escatimaban medios para desarrollarla. Por la crónica del rey Alfredo el Grande escrita por el monje Asser, sabemos que el rey era muy aficionado a escuchar poesía en inglés y a memorizarla; igualmente, Leoba era capaz de memorizar todo lo que leía o escuchaba ${ }^{140}$. Se consideraba, por ejemplo, que los niños muy pequeños poseían algún tipo de "memoria inconsciente", y que lo que aprendían a muy tierna edad lo retendrían para siempre. Rusticula recordaba los versículos que su nodriza le leía mientras ella dormía en su regazo, y en el monasterio femenino de Leoba se practicaba también la hipnopedia ${ }^{141}$. Así mismo se desarrollaron procedimientos mnemotécnicos, y a ello no es extraña la obsesión por explicar las cosas a partir de los orígenes o etimologías de las palabras, o aprender cantando, pues "la música alegra el alma y la modulación de la voz suaviza la fatiga de las obras" ${ }^{142}$. Era corriente que el maestro dictase a los muchachos lo que habían de aprender para el día siguiente, y estos lo escribían en sus tablillas y luego lo memorizaban ${ }^{143}$. San Isidoro recomendaba una reflexión prolongada sobre el texto leído, recogidos y en silencio, para interpretar el texto personalmente, y luego proceder a una discusión o "disputa" en común, eso sí, evitando cuestiones inútiles o contiendas enojosas en las que se falte a la caridad ${ }^{144}$. También los niños se ayudaban unos a otros a memorizar: "que cada década lea y escuche conjuntamente", dice la Regula Magistri ${ }^{145}$, y en el siglo IX, la Vita Maglorii

\footnotetext{
${ }^{139}$ P. RICHÉ, Education and culture, p. 470.

${ }^{140}$ Vida de Sta. Leoba, trad. ingl. por C.H. TALBOT, The Anglo-Saxon Missionaries, p. 211.

${ }^{141}$ Suzanne F. Wemple, Women in Frankish Society, Marriage and the Cloister. 500 to 900 , University of Pensylvania Press, 1981, pp. 175-81.

${ }^{142}$ ISIDORO, Etymol. 3 17. Cita F. MARTín HERNÁNDEZ, Formación del Clero en la Iglesia Visigótico-Mozárabe, p. 17-18.

${ }^{143}$ Vita Maglorii, AS, Oct. 10, 702: Cum quadam die a magistro lectionem reddere rogatus esset, inventa est in tabula ejus amplior quam ipse descripsisset litterarum insertio.

${ }^{144}$ Reg. monach. 7, 1-2. PL 83, 877.

${ }^{145}$ Regula Magistri, L: In una quoque decada ergo in his tribus horis, invidem et legant et audiant, vicebus litteras et psalmos ignorantibus ostendant.
} 
describe un episodio en el que los muchachos pidieron permiso para cruzar el río y en la otra orilla poder recitar en alto sin molestar a los mayores ${ }^{146}$.

Al final del "curso" los oblatos de las escuelas monásticas debían demostrar su aprovechamiento ante el abad, recitando los salmos de memoria y más tarde los himnos y otros textos sagrados ${ }^{147}$.

No es extraño, por tanto, que algunas personas llegaran a desarrollar su memoria de un modo que ahora consideraríamos de prodigioso. El abad Achivus de Agaune podía recordar prácticamente todo lo que leía, y conocía de memoria prácticamente la Biblia completa ${ }^{148}$, y Cassiodoro cita a un hombre ciego que conocía también perfectamente los textos sagrados ${ }^{149}$.

Con todo, a menudo era necesario un estímulo "físico" para animar a los niños al estudio, y así encontramos asiduamente menciones a castigos físicos, siguiendo la tradición antigua. Por ejemplo, San Agustín se lamenta en sus Confesiones ${ }^{150}$ :

A este fin me pusieron a la escuela para que aprendiera las letras, en las
cuales ignoraba yo, miserable, lo que había de utilidad. Con todo, si era
perezoso en aprenderlas, era azotado, sistema alabado por los mayores,
muchos de los cuales, que llevaron este género de vida antes que nosotros,
nos trazaron caminos tan trabajosos, por los que se nos obligaba a caminar,
multiplicando así el trabajo y el dolor de los hijos de Adán.

Porque todavía no conocía yo palabra de aquella lengua [=griego] y ya se me instaba con vehemencia, con crueles terrores y castigos, a que la aprendiera.

Cuando admite que las caricias y sonrisa de sus padres y amigos y la libre curiosidad son instrumentos didácticos mucho más efectivos.

Los ejemplos del uso de azotes y otros castigos pueden multiplicarse; bastarán algunos tomados de diferentes áreas geográficas y de diferentes siglos. A mediados del siglo V, Pedro Crisólogo, arzobispo de Rávena, se pronunciaba así ante la emperatriz Gala Placidia ${ }^{151}$ :

Para aprender las formas de las letras y los rudimentos de la educación, $¿$ acaso no fuiste enviado a un maestro o inscrito en una escuela? Entonces, enteramente preparado para soportar esfuerzo y dolor, ¿no excusaste visitar tu casa y a tu familia? Pero, ¿Cuán útil fue para ti ser asignado a un profesor o enviado a una escuela? Por medio del esfuerzo y los castigos que se te infligían, el profesor te compelía a concebir el deseo de aprender aquellos rudimentos y a hacerte digno de atender a tan importantes lecciones.

\footnotetext{
${ }^{146}$ Vita Maglorii, 24. AASS, Oct. X, 782.

${ }^{147}$ Regula Magistri, c. 50.

${ }^{148}$ Vita Abbatum Acaunensium, 9. MGH, SRM, III, 179, 1. 12.

${ }^{149}$ Instituciones, 1-5.

${ }^{150}$ Confesiones, I, 9, 14 y I. 14, 23.

${ }^{151}$ Sermo 101. Citado por N. EVERETT, Literacy in Lombard Italy, p. 37-38.
} 
En la España visigoda, San Braulio recuerda cómo le ardían las manos por los golpes de palmeta que le daba su hermano Juan, entonces obispo de Zaragoza ${ }^{152}$, y hubo alguna ocasión de que por miedo a los azotes y castigos del maestro los niños llegaron a refugiarse en una iglesia como lugar sagrado $^{153}$. Y en la Inglaterra del siglo $\mathrm{X}$, los coloquios de Ælfric nos muestran a los muchachos perezosos siendo azotados ${ }^{154}$. Finalmente, en el 937, para escapar del castigo, los niños de San Gall prendieron fuego al cobertizo donde se guardaban los látigos; su miedo, para nosotros justificado, acabó con un pavoroso incendio que destruyó la mayor parte del monasterio $^{155}$.

Pero la vara no era el único método empleado. Ante todo, el maestro debía enseñar de modo que su ejemplo no contradijera su palabra. Varios legisladores monásticos, comenzado por San Benito ${ }^{156}$, recomiendan la paciencia y la benevolencia con los muchachos,

porque incluso si se usa [el castigo físico] contra los monjes estúpidos o negligentes, tal medida podría hacer a los niños peores que antes y no mejorarlos en absoluto.

También Paulo Diácono ${ }^{157}$ y Egberto de Lieja $^{158}$, por ejemplo, protestaron por los castigos inmoderados, y San Anselmo, reprochó a cierto abad que se le quejaba de no conseguir resultados con los niños, ni siquiera castigándolos y azotándolos continuamente, y alegó que tales métodos eran totalmente inefectivos, puesto que los niños no podían esperar nada bueno de él y aunque le temían no sentían por él ningún afecto ${ }^{159}$.

El incentivo de la golosina, específicamente infantil, se ofrecía para incitar el esfuerzo intelectual o para recompensar una práctica demandada, como testimonia San Jerónimo en su carta a Gaudencio para la pequeña Pacatula: "que nuestra querida Pacatula", dice, "reciba esta pequeña carta para leerla más tarde, ahora se contenta con saber las letras del alfabeto,

${ }^{152}$ Epist. 2. PL 80, 657.

${ }^{153}$ Cit. F. MARTín, Formación del Clero, p. 18.

${ }^{154}$ Cit. N. ORME, Medieval Schools, p. 45-46. Por ejemplo, en el "diálogo 3", se lee: Crede mihi, uolo accusare te apud nostrum magistrum, quoniam uae facis nobis cotidie, et pene omni die propter stultitiam tuam flagellis ac uirgis durissimis cedimur a nostro papate, et ideo propter hoc corium tuum dimitiere debes... Ed. y trad. al inglés contemporáneo Scott GWARA y David W. PORTER, Anglo-Saxon Conversations. The Colloquies of Aelfric Bata, Bury St. Edmunds, 1997, pág. 84.

${ }^{155}$ Cit. D. LETT, The Child in Christendom, p. 39.

${ }^{156}$ Regula Sancti Benedicti, LIII. Sin embargo, San Benito consideraba apropiado el castigo físico para los niños menores de 15 años, si bien con moderación: Reg. LXX: Infantum vero usque quindecim annorum aetate disciplinae diligenta ab omnibus et custodia sit sed et hoc cum omni mensura et ratione.

${ }^{157}$ Comentario a la Regla de San Benito, ed. Bibliotheca Cassinensis, t. IV cha. LXIII, 1880 p. 124: Debent temperanter agere magister illorum erga illos et non illos flagellare nimis aut male tractare ... quia post flagellum vel disciplinam statim ad vana revertuntur. Cit. D. LETT, The Child in Christendom, p. 39-40, y P. RICHÉ, Education and Culture, p. 452.

${ }^{158}$ EgBerto De Lieja, Fecunda Ratis, ed. Voigt, Halle, 1889, p. 179. Cit. ibid.

${ }^{159}$ EADMER, Vita Anselmi 22. ed. R.W. Southern, Oxford, 1962, p. 37. 
juntar sílabas, aprender los nombres y conjugar los verbos; y para animarle a repetir con su voz de plata, que se la recompense con pastelitos de azúcar, que siempre son agradables al gusto" 160 .

\section{CONCLUSIONES}

En conclusión, el hueco dejado por la desaparición de la escuela pública fue llenado, a principios de la Alta Edad Media, en la medida de sus posibilidades por las distintas instancias eclesiásticas: parroquiales, episcopales y monásticas. De este modo, la Iglesia católica se convirtió, igual que en otros muchos aspectos, en garante de la transmisión de la cultura antigua a la posteridad

La distinción entre la enseñanza primaria y la secundaria no en esta época no estaba definida de forma precisa, como lo había estado en la época clásica, por lo que el adolescente que deseaba continuar su formación, sin solución de continuidad, pasaba al estudio de la gramática y profundizaba en sus lecturas de textos bíblicos y patrísticos sobre todo, de modo que tampoco existía una clara solución de continuidad entre los estudios religiosos y profanos.

Fecha de recepción: junio de 2009.

Fecha de aceptación y versión final: marzo 2010.

${ }^{160} \mathrm{Cit}, \mathrm{D}$. ALEXANDRE-BIDON, La Lettre volée: apprende à lire à l'enfant au moyen âge, "Annales", 44 (1989), 953-92, p. 973. 


\section{Figura 1}
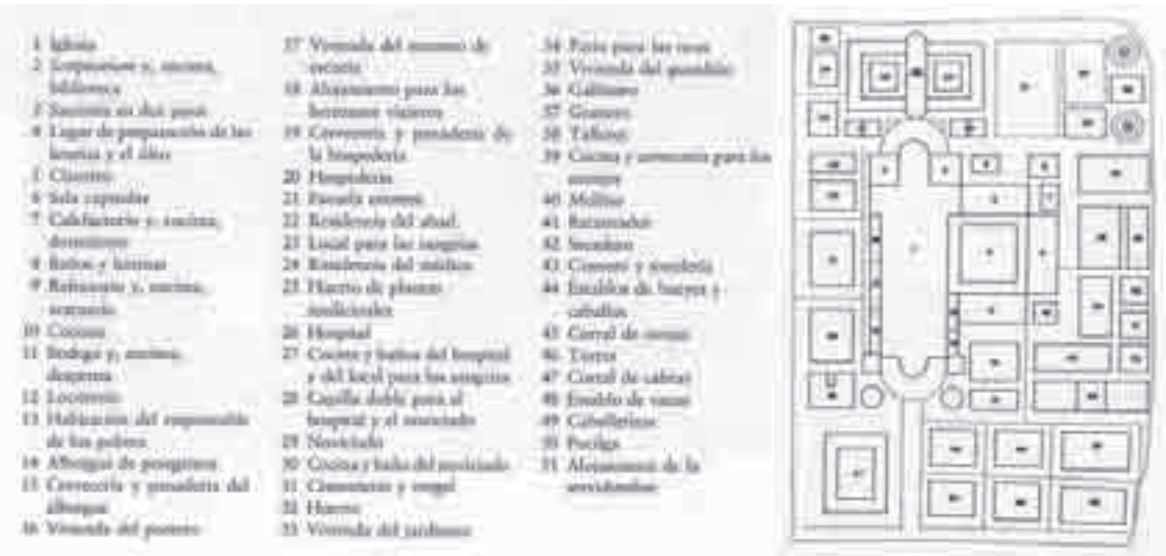

Plano de San Gall. Leyenda. Tomado de Heinz HoRAt, La arquitectura medieval de la Abadía de Sankt Gallen, en Werner Vogler (dir.), La Cultura de la Abadía de Sankt Gallen, Madrid, Encuentro, 1992, p. 196. 


\section{Figura 2}

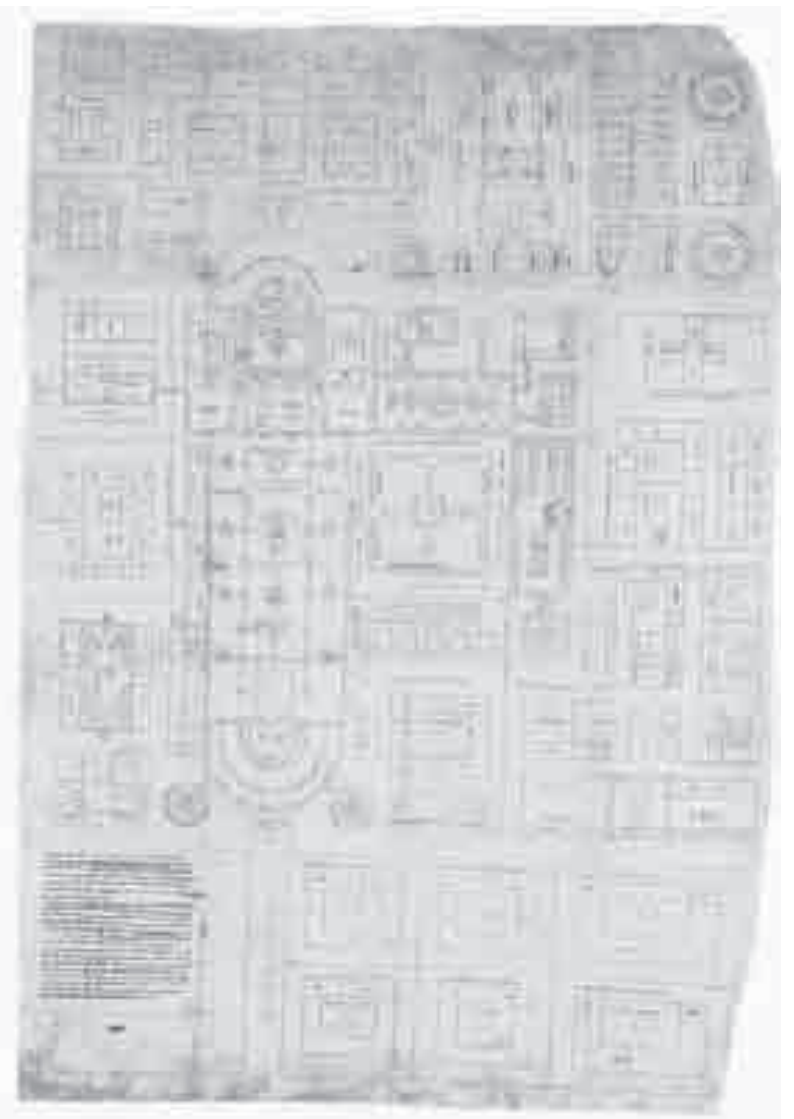

Plano de San Gall. Facsímil. Dibujado en Reichenau hacia 825 para San Gall. Cod. Sang. 1092. Tomado de Heinz Horat, La Arquitectura medieval de la Abadía de Sankt Gallen, en Werner Vogler (dir), La Cultura de la Abadía de Sankt Gallen, Madrid, Encuentro, 1992, p. 197. 
Figura 3

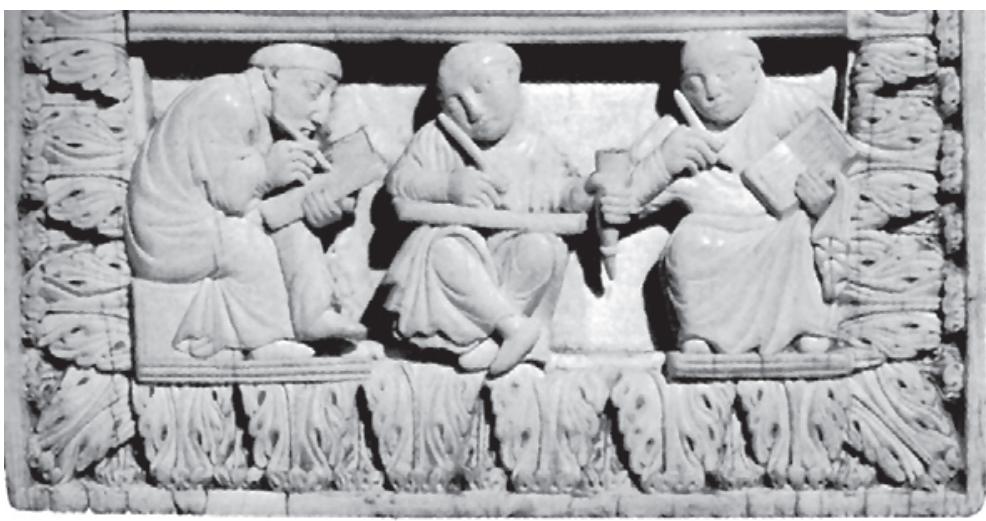

Escribas de Gregorio Magno. Detalle de la cubierta de marfil tallado, s. X, Viena, Kunsthistorische Museum, Der Hl. Gregor mit drei Screibern (Elfenbeinplatte, Inv. Nr. 8399). Tomado de Marc Drogin, Medieval Calligraphy, London, 1980, frontispicio. 